\title{
Non-Obese Type 2 Diabetic Rat Models-GK Rat and SDT Rat
}

\author{
Takeshi Ohta1 ${ }^{*}$, Tomohiko Sasase1, Takayuki Gotoh², Masami Shinohara ${ }^{3}$, \\ Phanthila Sirichaiyakul ${ }^{4}$, Suhattaya Furuta4, Rumpar Techasakulsin ${ }^{4}$, Taiichiro Kamiya4, \\ Chikako Yoshida5, Takahisa Yamada ${ }^{6}$
}

\author{
${ }^{1}$ Biological/Pharmacological Research Laboratories, Central Pharmaceutical Research Institute, Japan Tobacco Inc., Osaka, Japan \\ ${ }^{2}$ Technical Service Department, CLEA Japan Inc., Shizuoka, Japan \\ ${ }^{3}$ Tokyo Animal \& Diet Department, CLEA Japan Inc., Tokyo, Japan \\ ${ }^{4}$ Nomura Siam International Co. Ltd., Bangkok, Thailand \\ ${ }^{5}$ Field Center for Sustainable Agriculture and Forestry, Faculty of Agriculture, Niigata University, Niigata, Japan \\ ${ }^{6}$ Laboratory of Animal Genetics, Graduate School of Science and Technology, Niigata University, Niigata, Japan \\ Email: *takeshi.ota@jt.com
}

How to cite this paper: Ohta, T., Sasase, T., Gotoh, T., Shinohara, M., Sirichaiyakul, P., Furuta, S., Techasakulsin, R., Kamiya, T., Yoshida, C. and Yamada, T. (2018) Non-Obese Type 2 Diabetic Rat Models-GK Rat and SDT Rat. Open Journal of Animal Sciences, 8, 396-420.

https://doi.org/10.4236/ojas.2018.84030

Received: July 13, 2018

Accepted: September 10, 2018

Published: September 13, 2018

Copyright (C) 2018 by authors and Scientific Research Publishing Inc. This work is licensed under the Creative Commons Attribution International License (CC BY 4.0).

http://creativecommons.org/licenses/by/4.0/

\begin{abstract}
The number of diabetic patients has recently been increasing all over the world together with lifestyle changes including sedentary life and high-calorie diet intake, and as a result the increase in these suffering from diabetes mellitus has become a global issue. Diabetic animal models play a key role in bettering our understanding of the pathophysiology of diabetes and in developing new therapies for the disease. Diabetes is classified into two types, type 1 and type 2, and type 2 diabetes is chiefly caused by a depletion of insulin secretion in the pancreas and insulin resistance in peripheral tissues. The Goto-Kakizaki (GK) rat and the Spontaneously Diabetic Torii (SDT) rat are genetic non-obese type 2 diabetic models, and the both rats are considered to be suitable models for investigating the etiology of the depletion of insulin secretion and impaired glucose tolerance. In this review, we overviewed the outline of pathophysiological features in GK rats and SDT rats, including biological parameters and pharmacological responses.
\end{abstract}

\section{Keywords}

Diabetic Model, GK Rat, SDT Rat, Type 2 Diabetes

\section{Introduction}

Metabolic diseases, including diabetes, have become health issues worldwide, and the population of patients is rapidly increasing [1] [2] [3]. The growing 
population of diabetic patients has resulted in an increase in the number of patients who have micro-vascular complications, such as nephropathy, retinopathy, and neuropathy [4] [5] [6]. In addition to deterioration in the quality of life of such patients, the growing number of patients contributes to an increase in medical costs [7]. It is very important to prevent the development of diabetes; however, the etiology is complex, involving multiple mechanisms affecting multiple organs.

Diabetes is classified into two types, type 1 and type 2 diabetes, and most patients are suffering with type 2 diabetes. Type 2 diabetes is caused by a depletion of insulin secretion in the pancreas and a reduction of insulin sensitivity in peripheral tissues, such as the liver, muscles, and fat [8]. Animal models of type 2 diabetes have been established to assist better understanding of the pathophysiology of diabetes and its complications. Most of these models have abnormalities of single or multiple genes related to insulin deficiency, glucose intolerance, and/or insulin resistance leading to high blood glucose levels [9]. The development of diabetes and the progression of its complications are affected by various factors, including obesity, insulin resistance, hyperglycemia, and dyslipidemia. It is considered that in the future, diabetic animal models will play pivotal roles in development of new medical treatments.

The Goto-Kakizaki (GK) rat and the Spontaneously Diabetic Torii (SDT) rat are genetic non-obese type 2 diabetic models, and the rats are considered to be suitable models for investigating the etiology of the depletion of insulin secretion and impaired glucose tolerance. Non-obese type 2 diabetic models are classified into a non-genetic model and a genetic model. A neonatal rat injected with streptozotocin (nSTZ rat) is used as a non-genetic model. nSTZ rats show a chronic hyperglycemia with blood glucose concentrations ranging between 300 $400 \mathrm{mg} / \mathrm{dl}$, and a reduction of body weight occurs [10]. Moreover, the insulin secretion in response to glucose is markedly impaired [11] [12]. nSTZ rat model bears a resemblance to non-obese type 2 diabetes. In this review, we focus on a genetic model and introduce the pathophysiological features in GK rats and SDT rats.

\section{GK Rat}

\subsection{Background-Breeding and Gene Analysis}

GK rats were produced by a working hypothesis that posited that the repeating of the selective breeding of Wistar rats, a normal rat, with a slight glucose intolerance would lead to the production of a new spontaneous diabetic rat [13]. Firstly, 211 Wistar rats were prepared, and 18 rats were selected for breeding by an oral glucose tolerance test (OGTT). Furthermore, through the breeding, 162 offsprings ( $\mathrm{F}_{1}$ rats) were obtained. By repetition of the selective breeding, $204 \mathrm{~F}_{2}$, $174 \mathrm{~F}_{3}$ and $215 \mathrm{~F}_{4}$ rats were obtained. As a result, the glucose tolerance curve became more diabetic with the increasing number of generations, and the positive rate in the urine sugar test during OGTT increased. In $\mathrm{F}_{3}$ generations, the fasting 
blood glucose levels were significantly increased (Male rats: 83 - $144 \mathrm{mg} / \mathrm{dl}, \mathrm{Fe}-$ male rats: $77-126 \mathrm{mg} / \mathrm{dl}$ ). In the first experiment, sib-breeding has been avoided; however, in the subsequent experiment, brother-sister breeding was performed to intensify the nature of hyperglycemia in GK rats.

The GK rat is a polygenic strain and spontaneously develops diabetes. A comprehensive study of the genetic basis of diabetes in GK rats has been performed. The genetic dissection of non-insulin dependent diabetes mellitus (NIDDM) has allowed us to map three independent loci involved in the disease. Also, a major factor affecting body weight on chromosome 7 and map a further 10 regions that are suggestive for linkage are identified [14]. Furthermore, a combination of physiological and genetic studies was performed to identify quantitative trait loci (QTLs) responsible for the control of insulin secretion and glucose homeostasis in a $\mathrm{F}_{2}$ cohort bred from GK rats. The genetic dissection of NIDDM allowed us to map up to six independently segregating loci predisposing to hyperglycemia, impaired glucose tolerance or impaired insulin secretion, and a seventh locus implicated in body weight [15].

\subsection{Biological Profiles-Body Weight and Blood Chemical Parameters}

Biological parameters, including body weight and blood biochemical levels, were determined in our institutes. Ten male and 10 female GK rats were prepared. Thirty male and 30 female Wistar rats were prepared as control rats. The body weights in GK rats and Wistar rats were measured every 2 weeks, from 4 to 18 weeks of age (Figure 1). The non-fasting glucose levels in GK rats were measured every 2 weeks, from 4 to 18 weeks of age, and the non-fasting glucose levels in Wistar rats, a normal control rat, were measured at 4,10 , and 18 weeks of age (Figure 2). The $2 \mathrm{~g} / \mathrm{kg}$ OGTT ( $16 \mathrm{~h}$ fasting) was performed at 10 weeks of age in GK rats and Wistar rats (Figure 3 and Figure 4). The rats were fed CE-2, a standard diet (CLEA Japan, Tokyo, Japan).

Changes in the body weight are shown in Figure 1. Body weights in male GK rats showed lower levels as compared with those in male Wistar rats during the observational period (body weights at 6 weeks of age, GK rats: $127.3 \pm 4.0 \mathrm{~g}$ vs. Wistar rats: $146.2 \pm 5.1 \mathrm{~g}$; body weights at 18 weeks of age, GK rats: $327.4 \pm 10.6 \mathrm{~g}$ vs. Wistar rats: $393.9 \pm 22.5 \mathrm{~g}$ ) (Figure $1(\mathrm{~A})$ ). On the other hand, body weights in female GK rats were comparable to those in female Wistar rats during the observational period (Figure 1(B)). It was suggested that the male GK rat was a non-obese diabetic model.

Changes in the non-fasting glucose levels were shown in Figure 2. The male GK rats showed an increase of the glucose levels at 4 weeks of age (GK rats: $172.0 \pm 16.2 \mathrm{mg} / \mathrm{dl}$ vs. Wistar rats: $46.6 \pm 6.8 \mathrm{mg} / \mathrm{dl}$ ), and the hyperglycemia was sustained during the observational period (glucose levels at 18 weeks of age, GK rats: $190.0 \pm 14.2 \mathrm{mg} / \mathrm{dl}$ vs. Wistar rats: $105.9 \pm 11.4 \mathrm{mg} / \mathrm{dl}$ ) (Figure 2(A)). Also, in female GK rats, the blood glucose level at 4 weeks of age increased as compared with that in female Wistar rats (GK rats: $199.0 \pm 19.8 \mathrm{mg} / \mathrm{dl}$ vs. Wistar 


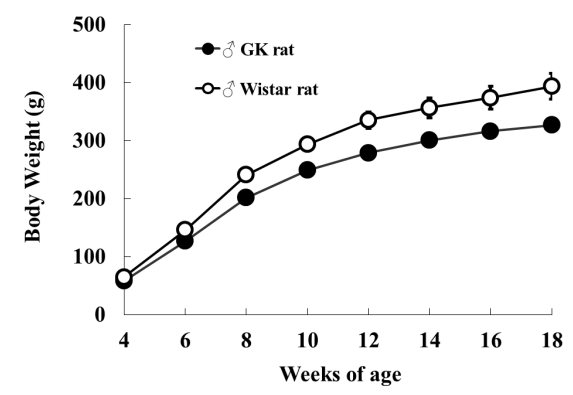

(A)

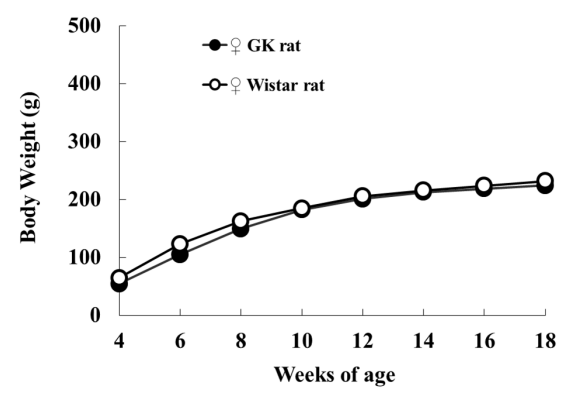

(B)

Figure 1. Changes in body weights in GK rats and Wistar rats from 4 to 18 weeks of age. (A) Male GK rats $(n=10)$ and Wistar rats $(\mathrm{n}=30)$; (B) Female GK rats $(\mathrm{n}=10)$ and Wistar rats $(\mathrm{n}=30)$.

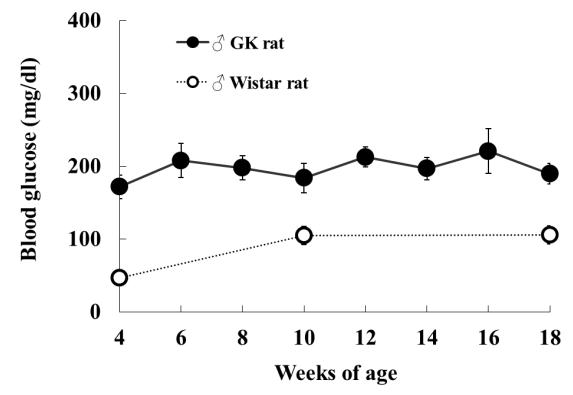

(A)

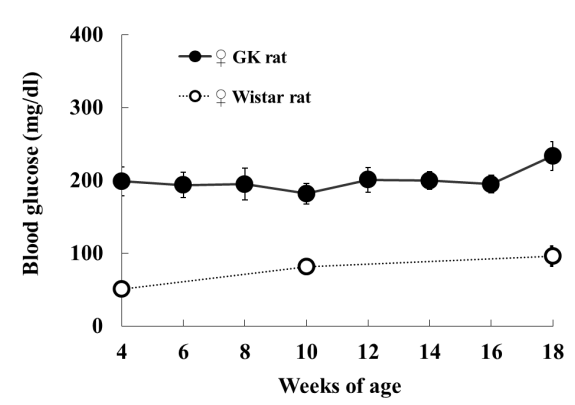

(B)

Figure 2. Changes in blood glucose levels in GK rats and Wistar rats from 4 to 18 weeks of age. (A) Male GK rats ( $\mathrm{n}=10)$ and Wistar rats $(\mathrm{n}=30)$; (B) Female GK rats $(\mathrm{n}=10)$ and Wistar rats $(\mathrm{n}=30)$.

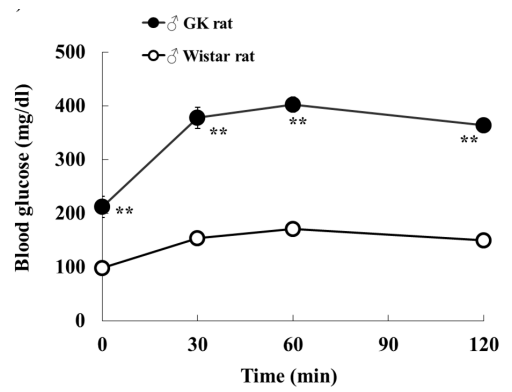

(A)

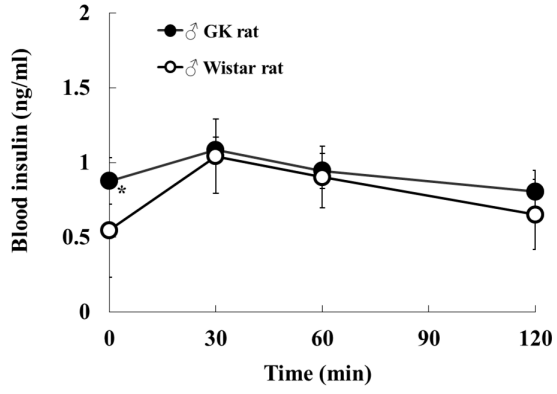

(B)

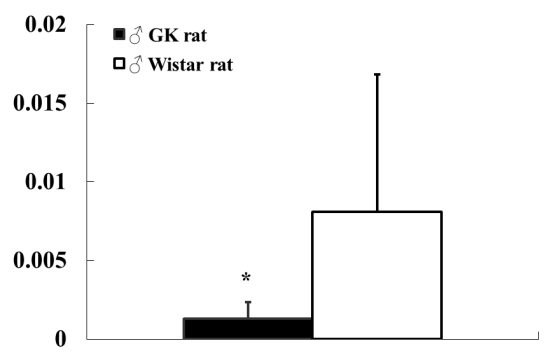

(C)

Figure 3. Changes in blood glucose (A) and insulin (B) levels in male glucose-loaded GK rats and Wistar rats at 10 weeks of age; (C) Insulinogenic index in glucose-loaded GK rats and Wistar rats. Insulinogenic index $=\Delta$ Insulin (increment from $0-30$ $\mathrm{min}) / \Delta$ Glucose (increment from 0 - $30 \mathrm{~min})$. Data represent mean \pm standard deviation $(\mathrm{n}=10) .{ }^{*} \mathrm{P}<0.05,{ }^{* *} \mathrm{P}<0.01$; significantly different from the Wistar rat. 


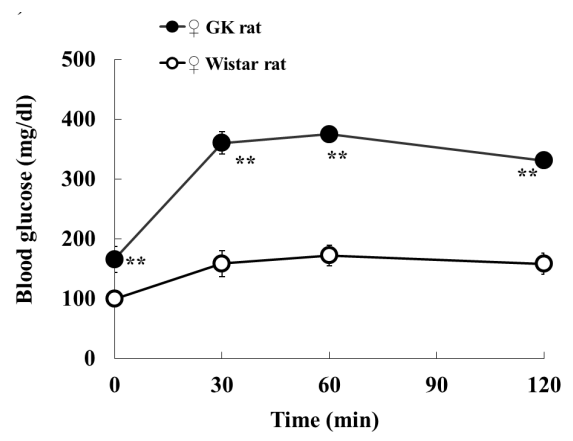

(A)

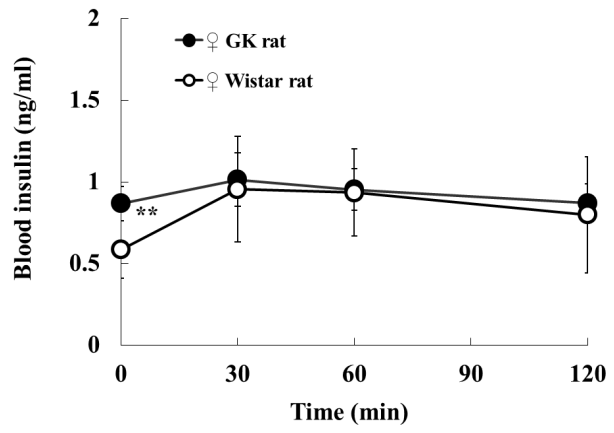

(B)

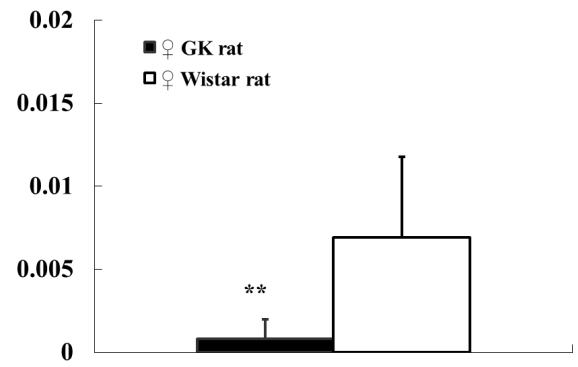

(C)

Figure 4. Changes in blood glucose (A) and insulin (B) levels in female glucose-loaded GK rats and Wistar rats at 10 weeks of age; (C) Insulinogenic index in glucose-loaded GK rats and Wistar rats. Data represent mean \pm standard deviation $(\mathrm{n}=10) .{ }^{\star} \mathrm{P}<0.05,{ }^{\star *} \mathrm{P}<$ 0.01 ; significantly different from the Wistar rat.

rats: $51.4 \pm 7.8 \mathrm{mg} / \mathrm{dl}$ ), and the hyperglycemia was sustained until 18 weeks of age (GK rats: $234.0 \pm 19.8 \mathrm{mg} / \mathrm{dl}$ vs. Wistar rats: $96.5 \pm 13.0 \mathrm{mg} / \mathrm{dl}$ ) (Figure 2(B)).

Changes in the blood glucose and insulin levels in OGTT were shown in Figure 3 and Figure 4. In OGTT of GK rats, we investigated the GSIS as well as the glucose intolerance. Also, the insulin sensitivity was examined by measuring the fasted glucose and insulin levels. The blood glucose levels in male GK rats significantly increased at 30,60, and $120 \mathrm{~min}$. after glucose-loading, as compared with those in male Wistar rats (Figure $3(\mathrm{~A})$ ). Moreover, the fasting glucose level (0 min.) significantly increased in male GK rats (GK rats: $212.1 \pm 19.9 \mathrm{mg} / \mathrm{dl} \mathrm{vs}$. Wistar rats: $98.3 \pm 9.3 \mathrm{mg} / \mathrm{dl}$ ). The blood insulin levels after glucose-loading in male GK rats were comparable to those in male Wistar rats; however, the fasting 
insulin level $(0 \mathrm{~min}$.) significantly increased in the GK rats (GK rats: $0.877 \pm$ $0.155 \mathrm{ng} / \mathrm{ml}$ vs. Wistar rats: $0.547 \pm 0.312 \mathrm{ng} / \mathrm{ml}$ ) (Figure $3(\mathrm{~B})$ ). Moreover, the insulinogenic index in GK rats was significantly reduced as compared with that in Wistar rats (Figure $3(C)$ ). The insulinogenic index ( $\Delta$ Insulin/ $\Delta$ Glucose) was calculated using incremental plasma insulin and glucose levels for 0 to $30 \mathrm{~min}$ after glucose-loading. Also, in female GK rats, the blood glucose levels after glucose-loading significantly increased, and the fasting glucose level (0 min.) increased in female GK rats (GK rats: $166.0 \pm 22.0 \mathrm{mg} / \mathrm{dl}$ vs. Wistar rats: $99.8 \pm$ $10.3 \mathrm{mg} / \mathrm{dl}$ ) (Figure 4(A)). The blood insulin levels after glucose-loading in female GK rats were comparable to those in female Wistar rats, and the fasting insulin level $(0 \mathrm{~min}$.) significantly increased in the GK rats (GK rats: $0.868 \pm$ $0.104 \mathrm{ng} / \mathrm{ml}$ vs. Wistar rats: $0.586 \pm 0.176 \mathrm{ng} / \mathrm{ml}$ ) (Figure $4(B)$ ). Furthermore, the insulinogenic index in GK rats significantly decreased as compared with that in Wistar rats (Figure 4(C)). GK rats showed an impaired glucose tolerance with the depletion of glucose-stimulated insulin secretion (GSIS). In addition, GK rats represented with a significant reduction of the insulinogenic index, suggesting that the early phase of insulin secretion after glucose-loading was characteristically impaired. In the previous reports, also, GK rats showed a reduction of GSIS, and in particular, the early phase of glucose-induced secretion was impaired [16] [17].

Several blood biochemical parameters were measured at 5, 10, and 18 weeks of age (Table 1). The TG levels in male and female GK rats were decreased by age (Table 1(a) and Table 1(b)). The decrease in TG levels may be related to the non-fasted insulin levels. Functional parameters in the kidneys, such as blood urea nitrogen (BUN) and blood creatinine, showed higher levels in GK rats than in Wistar rats.

\subsection{Insulin Sensitivity}

Villar-Palasi and Farese reported on the insulin sensitivity in peripheral tissues of GK rats in 1994 [18]. Glycogen synthase (GS) activity, GS phosphatase activity, and glucose 6-phosphatase (G6P) content after insulin treatment in skeletal muscle increased in Wistar rats, but, in GK rats, no increases in GS phosphate and G6P were observed. In adipose tissue, the activation of GS after insulin treatment was normal in GK rats. A defective activation of glucose accumulation into glycogen in skeletal muscle may be related to the impaired glucose tolerance and hyperglycemia in the GK rat. In the liver of GK rats, the G6P and the fructose-1,6-diphosphative activities increased, and the phosphofructokinase (PFK) was reduced, suggesting that the gluconeogenesis increased and the glycolysis decreased. Meanwhile, the activities of insulin-inducible enzyme, such as glucokinase and pyruvate kinase increased in the liver at 4 and 12 weeks of age in GK rats [19]. Those changes in hepatic enzyme are similar with those in adult-onset diabetic patients [20]. GK rats showed increases in fasting blood glucose and insulin levels (Figure 3 and Figure 4), indicating that insulin sensitivity in the liver was reduced in GK rats. 
Table 1. (a) Blood chemical parameters in male GK rats and Wistar rats; (b) Blood chemical parameters in female GK rats and Wistar rats.

(a)

\begin{tabular}{|c|c|c|c|c|}
\hline & & 5 weeks-old & 10 weeks-old & 18 weeks-old \\
\hline \multirow{7}{*}{ GK rat } & TG (mg/dl) & $139.9 \pm 30.0$ & $72.4 \pm 10.7$ & $59.2 \pm 9.0$ \\
\hline & $\underline{\mathrm{TC}}(\mathrm{mg} / \mathrm{dl})$ & $63.8 \pm 1.8$ & $54.5 \pm 4.2$ & $65.4 \pm 7.5$ \\
\hline & GPT (U/1) & $48.7 \pm 4.6$ & $43.5 \pm 4.9$ & $44.0 \pm 10.1$ \\
\hline & GOT (U/1) & $55.2 \pm 13.3$ & $45.3 \pm 8.9$ & $58.9 \pm 11.9$ \\
\hline & $\underline{\mathrm{TP}}(\mathrm{g} / \mathrm{l})$ & $5.47 \pm 0.14$ & $6.28 \pm 0.22$ & $6.38 \pm 1.40$ \\
\hline & $\underline{\text { BUN }(\mathrm{mg} / \mathrm{dl})}$ & $24.8 \pm 1.6$ & $22.3 \pm 1.3$ & $24.7 \pm 3.7$ \\
\hline & CRE (mg/dl) & $0.42 \pm 0.02$ & $0.58 \pm 0.06$ & $0.64 \pm 0.06$ \\
\hline \multirow{7}{*}{ Wistar rat } & $\mathrm{TG}(\mathrm{mg} / \mathrm{dl})$ & $132.5 \pm 50.0$ & $77.5 \pm 15.7$ & $128.9 \pm 29.8$ \\
\hline & $\underline{\mathrm{TC}}(\mathrm{mg} / \mathrm{dl})$ & $89.4 \pm 9.8$ & $59.5 \pm 7.0$ & $67.4 \pm 5.4$ \\
\hline & GPT (U/l) & $49.2 \pm 8.2$ & $34.0 \pm 3.6$ & $50.0 \pm 6.9$ \\
\hline & GOT (U/l) & $78.2 \pm 6.6$ & $61.2 \pm 6.8$ & $66.2 \pm 6.8$ \\
\hline & $\underline{\mathrm{TP}}(\mathrm{g} / \mathrm{l})$ & $5.11 \pm 0.14$ & $6.14 \pm 0.19$ & $6.75 \pm 0.42$ \\
\hline & $\underline{\mathrm{BUN}}(\mathrm{mg} / \mathrm{dl})$ & $13.3 \pm 2.0$ & $15.9 \pm 1.7$ & $16.8 \pm 1.5$ \\
\hline & CRE (mg/dl) & $0.16 \pm 0.01$ & $0.29 \pm 0.06$ & $0.30 \pm 0.02$ \\
\hline
\end{tabular}

TG: triglyceride, TC: total cholesterol, GPT: glutamic pyruvic transaminase; GOT: glutamic oxaloacetic transaminase, TP: total protein, BUN: blood urea nitrogen; CRE: creatinine.

(b)

\begin{tabular}{|c|c|c|c|c|}
\hline & & 5 weeks-old & 10 weeks-old & 18 weeks-old \\
\hline \multirow{7}{*}{ GK rat } & TG (mg/dl) & $258.0 \pm 25.0$ & $125.7 \pm 26.0$ & $70.9 \pm 19.7$ \\
\hline & $\mathrm{TC}(\mathrm{mg} / \mathrm{dl})$ & $73.5 \pm 4.2$ & $58.6 \pm 4.8$ & $70.4 \pm 12.8$ \\
\hline & GPT (U/l) & $41.2 \pm 3.4$ & $36.2 \pm 2.5$ & $37.6 \pm 9.1$ \\
\hline & GOT (U/l) & $56.2 \pm 6.6$ & $39.0 \pm 5.7$ & $47.9 \pm 3.4$ \\
\hline & $\underline{\mathrm{TP}}(\mathrm{g} / \mathrm{l})$ & $5.59 \pm 0.12$ & $6.27 \pm 0.25$ & $6.72 \pm 1.05$ \\
\hline & BUN (mg/dl) & $22.5 \pm 1.0$ & $17.2 \pm 1.7$ & $20.4 \pm 5.1$ \\
\hline & CRE (mg/dl) & $0.42 \pm 0.04$ & $0.54 \pm 0.03$ & $0.66 \pm 0.11$ \\
\hline \multirow{7}{*}{ Wistar rat } & TG (mg/dl) & $148.4 \pm 35.0$ & $51.1 \pm 14.2$ & $67.8 \pm 13.3$ \\
\hline & $\underline{\mathrm{TC}}(\mathrm{mg} / \mathrm{dl})$ & $82.1 \pm 11.1$ & $57.9 \pm 8.8$ & $66.7 \pm 6.8$ \\
\hline & GPT (U/1) & $38.8 \pm 3.5$ & $35.9 \pm 6.7$ & $34.6 \pm 4.0$ \\
\hline & GOT (U/l) & $70.0 \pm 5.7$ & $65.7 \pm 12.3$ & $55.2 \pm 5.1$ \\
\hline & $\underline{\mathrm{TP}}(\mathrm{g} / \mathrm{l})$ & $5.29 \pm 0.34$ & $5.99 \pm 0.45$ & $6.87 \pm 0.25$ \\
\hline & $\underline{\mathrm{BUN}}(\mathrm{mg} / \mathrm{dl})$ & $15.2 \pm 2.5$ & $15.6 \pm 3.2$ & $17.4 \pm 2.0$ \\
\hline & CRE (mg/dl) & $0.17 \pm 0.02$ & $0.27 \pm 0.02$ & $0.33 \pm 0.04$ \\
\hline
\end{tabular}

TG: triglyceride, TC: total cholesterol, GPT: glutamic pyruvic transaminase; GOT: glutamic oxaloacetic transaminase, TP: total protein, BUN: blood urea nitrogen; CRE: creatinine. 


\subsection{Diabetic Complications}

Peripheral neuropathy in GK rats has been been examined by Yagihashi et al. [21]. The motor nerve conduction velocity (MNCV) of the tail was always lower in GK rats than in age-matched Wistar rats, from 2 to 8 months of age (MNCV at 2 months of age, GK rats: $36.6 \pm 2.4 \mathrm{~m} / \mathrm{s}$ vs. Wistar rats: $40.4 \pm 1.8 \mathrm{~m} / \mathrm{s}$; MNCV at 8 months of age, GK rats: $53.6 \pm 4.4 \mathrm{~m} / \mathrm{s}$ vs. Wistar rats: $63.5 \pm 4.8 \mathrm{~m} / \mathrm{s}$ ). In morphometrical analysis of peripheral nerves, GK rats showed a reduction in the caliber of unmyelinated axons at 2 months of age, and the endoneural space was widened at 3 months of age. Furthermore, loss of myelinated nerve fibers, and decreases in nerve fiber size and axonal size were observed at 6 months of age in GK rats. Metabolic abnormalities in the polyol pathway are considered to be related to the development of neuropathy. Sustained hyperglycemia promotes the polyol pathway and the accumulation of sorbitol in neural fibers, resulting in the deterioration of neural function via hyperosmosis [22]. In particular, the decrease in the activity of sodium-potassium-ATPase associated with defects of myo-inositol by sorbitol accumulation is closely related with the decrease in MNCV [23].

Urinary albumin excretion (UAE) was significantly higher in GK rats than in Wistar rats, from 2 to 14 months of age, and the UAE levels rose progressively over time [24]. Also, Yagihashi et al. have investigated the glomerular lesion in GK rats [25]. Creatinine clearance decreased over time in GK rats, but not in Wistar rats. Blood pressure in GK rats was in the normotensive range. In GK rats at 8 weeks of age, there was no significant difference in ultrastructure from age-matched Wistar rats. At 12 weeks of age, GK rats showed thickening of basement membrane and accumulation of basement membrane-like materials in the mesangial regions. After 16 to 24 weeks of age in GK rats, hemispherical thickening in addition to diffuse thickening of the glomerular basement membrane was observed. Moreover, interstitial monocyte/macrophage influx in GK rats increased at 12 weeks of age, as compared with that in Wistar rats [26]. Glomerular macrophage infiltration was also elevated in GK rats at 35 weeks of age. The histological changes observed in GK rats are similar to those observed in prolonged type 2 diabetic patients who have not developed renal lesions. In brief, the GK rat is useful in investigating the mechanism involved in the pathogenesis of the consequences of sustained hyperglycemia.

There are some reports in which renal lesions in GK rats were investigated. The dye-dilution technique with scanning laser ophthalmoscope-based fluorescein angiopathy was performed to evaluate retinal circulation in GK rats at 1, 3 , and 5 months of age [27]. The retinal mean circulation times (MCTs) in GK rats were always prolonged, as compared with those in Wistar rats. No significant differences were observed in the retinal arterial and venous diameters in GK rats at each time period, but the retinal segmental blood flows (SBFs) were reduced in GK rats. The endothelial/pericyte $(\mathrm{E} / \mathrm{P})$ ratio in the retinas of GK rats was also investigated [28]. The E/P ratio was found to be higher in GK rats at 8 
months of age, and, in GK rats at 24 to 30 months of age, the $\mathrm{E} / \mathrm{P}$ ratio was higher than at 8 months of age. Moreover, time-dependent changes of electroretinograms (ERGs) have been determined in GK rats, 4 to 48 weeks of age [29]. The amplitudes of the a-wave, b-wave, and oscillatory potentials in GK rats were reduced with aging, and the a-wave latencies in GK rats were prolonged, as compared with those in Wistar rats. Functional abnormalities of photoreceptors might be induced by the prolonged hyperglycemia in GK rats.

\subsection{Pharmacological Study}

In a previous study, we investigated the pharmacological effects of JTT-608, a glucose-sensor activator, in comparison with the sulphonylurea tolbutamide in GK rats [30]. In isolated perfused pancreases from GK rats, JTT-608 enhanced the insulin secretion depending on glucose concentration $(2.8-11.1 \mathrm{mmol} / \mathrm{l})$; however, the tolbutamide stimulated insulin secretion at low glucose concentration (2.8 mmol/l). Moreover, JTT-608 stimulated insulin secretion in the first and second phase, but the tolbutamide enhanced only the second phase of insulin secretion. Also, in in vivo study, JTT-608 enhanced early insulin secretion only with glucose-loading. Furthermore, we investigated the chronic effect of JTT-608 in GK rats [31]. The fasting glucose and hemoglobin ( $\mathrm{Hb}$ ) A1c levels were reduced by JTT-608 treatment during the experimental period. In histopathological analysis, the decrease of insulin content in pancreas and the onset of renal lesions, vacuolation in renal tubules (Armanni-Ebstein changes), were improved with JTT-608 treatment (Figure 5).

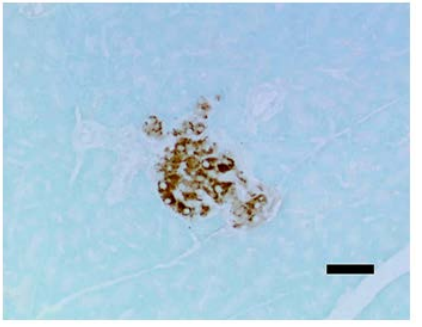

(A)

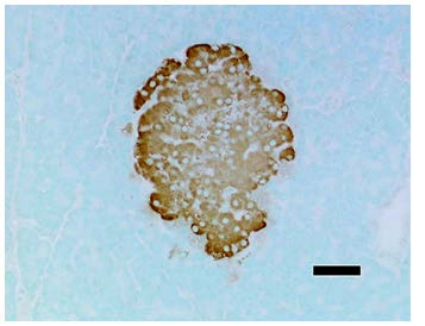

(B)

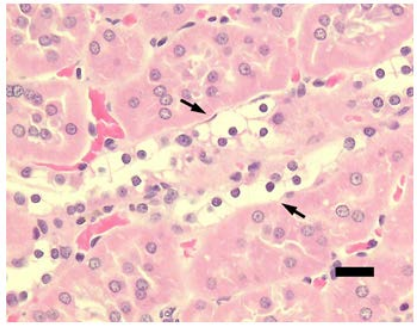

(C)

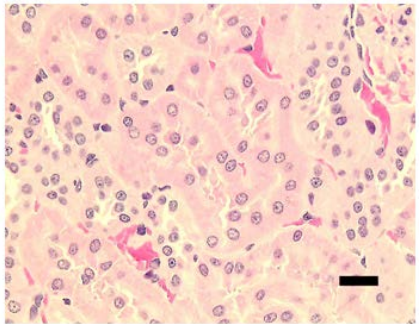

(D)

Figure 5. Histopathological analysis in GK rats with JTT-608 treatment. (A) Pancreas, GK rat at 18 weeks of age, immunostained with anti-insulin; (B) Pancreas, GK rat with JTT-608 treatment, immunostained with anti-insulin; (C) Kidney, GK rat at 18 weeks of age, hematoxylin and eosin staining. Arrows show Armanni-Ebstein changes; (D) Kidney, GK rat with JTT-608 treatment, hematoxylin and eosin staining. Bar $=20 \mu \mathrm{m}$. 
The effects of dipeptidyl peptidase (DPP)-4 inhibitors on the pancreas in GK rats were investigated. Chronic administration of vildagliptin for 18 weeks improved the glucose tolerance and insulin secretion, and suppressed hyperglucagonemia in GK rats [32]. Moreover, vildagliptin enhanced the $\beta$ cell and $\alpha$ cell proliferation, and increased the number of small neogenetic islets. It is reported that the perturbations of exocrine pancreatic function and structure in GK rats are improved by the long-term administration of vildagliptin [33].

The effects of sodium-glucose cotransporter (SGLT) inhibitor T-1095 were also investigated in GK rats [34]. T-1095 was administered as a dietary admixture for 32 weeks, from 7 to 9 weeks of age. As a result, T-1095 treatment decreased blood glucose and HbAlc levels in GK rats. Furthermore, T-1095 treatment prevented the development of diabetic neuropathy, such as reduction of the thermal response in tail-flick testing, in GK rats. In this way, the GK rat has been used for the development of new anti-diabetic drugs.

\section{SDT Rat}

\subsection{Background-Breeding and Gene Analysis}

SDT rat is an inbred strain of Sprague-Dawley (SD) rat established by Shinohara in 1997. Some non-obese diabetic rats which show polyphagia, polyposia, polyuria, and urinary sugar among approximately 1-year-old male SD rats were bred at the laboratory of Torii Pharmaceutical Co. Ltd. (Tokyo, Japan). These male $\mathrm{SD}$ rats were mated with normal female $\mathrm{SD}$ rats to generate diabetic $\mathrm{F}_{1}$ [35] [36] [37]. In the process of strain breeding, the incidence of diabetes in male rats was $90 \%$ or more in the $\mathrm{F}_{4}$ generation and $100 \%$ in the $\mathrm{F}_{9}$ and subsequent generations [35]. Diabetes tended to develop earlier in later generations and developed at approximately 4 months of age in the $\mathrm{F}_{7}$. Hypoinsulinemia accompanied by hyperglycemia appeared at approximately 20 weeks of age in male SDT rats. The cumulative incidence of diabetes was $100 \%$ by 40 weeks of age in male SDT rats, while it was only $33 \%$ in females even at 65 weeks.

Onset and development of diabetes in SDT rats are genetically regulated, and seven QTLs involved in glucose intolerance were mapped on the rat genome [38] [39]. In a backcross analysis with Brown Norway rats, QTLs involved in glucose intolerance in SDT rats were identified on chromosomes 1, 2, and X (Gisdt1, Gisdt2, and Gisdt3, respectively). In an intercross analysis with F344 rats, QTLs involved in glucose intolerance in SDT rats were identified on chromosomes 3, 8, 13, and 14 (Dmsdt1, Dmsdt2, Dmsdt3, and Dmsdt4, respectively). Moreover, Dmsdt1 was the major locus responsible for the pancreatic lesions in SDT rats [39].

\subsection{Biological Profiles-Phenotype and Blood Chemical Parameters}

Male SDT rats developed diabetes around 20 weeks of age and at 40 weeks of age, all animals developed diabetes (Figure 6(A)). However, only $1 / 3$ of female 


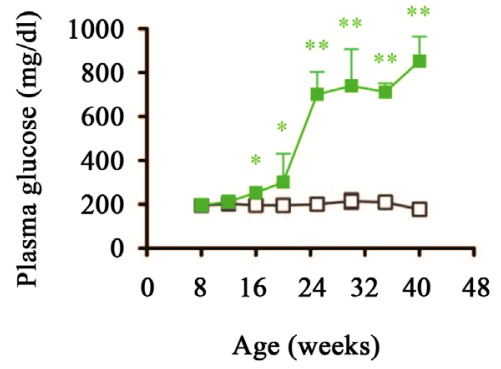

(A)

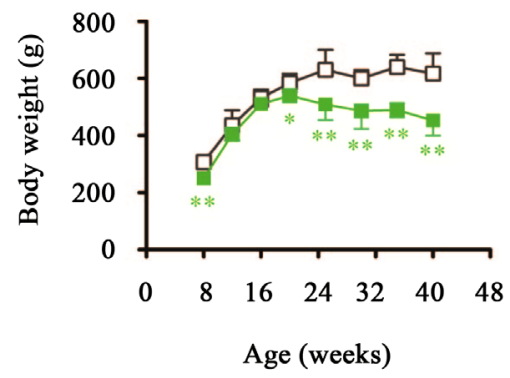

(C)

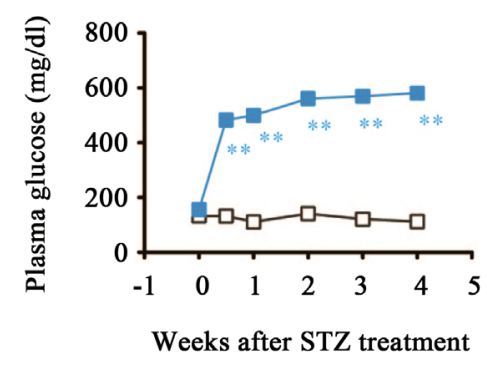

(B)

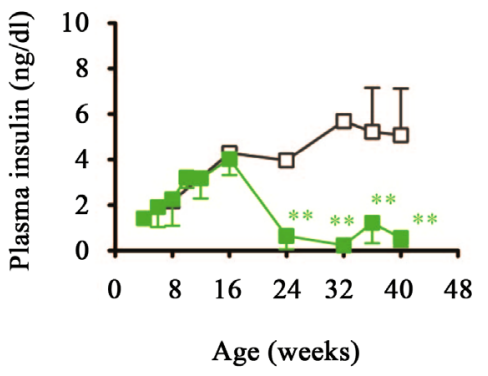

(D)

Figure 6. Biological profiles of male SDT rats. The plasma glucose levels in SDT rats become increase around 16 weeks of age and reached $700 \mathrm{mg} / \mathrm{dl}$ by 25 weeks (A); On the other hands, STZ-induced diabetic rats develop hyperglycemia immediately after STZ treatment (B); SDT rats show decreased body weight from 20 weeks of age (C); Blood insulin rapidly diminishes after 16 weeks of age (D). White square; male SD rats, green square; male SDT rats, blue square; STZ-induced diabetic rats. Data represent means \pm standard deviation $(\mathrm{n}=5-8) .{ }^{\star} \mathrm{P}<0.05,{ }^{* *} \mathrm{P}<0.01$; significantly different from the control SD rat. (A) - (C) are modified from [36] [37].

SDT rats developed diabetes, even at 65 weeks of age [37]. After the onset of diabetes, blood glucose level markedly increased and reached 800 to $1000 \mathrm{mg} / \mathrm{dl}$ at 30 weeks of age with polyuria/glucosuria as well as polyposia/polyphagia. HbAlc increased to more than $10 \%$. One of the most popular animal models, STZ-induced diabetes rats, also showed severe hyperglycemia within a day after STZ injection (Figure 6(B)). This is a clear difference between spontaneous model and chemical induced models. Our preliminary study showed that polyphagia and obesity result from ventromedial hypothalamic (VMH) damage developed diabetes earlier than sham operated SDT rats (Ito and Sasase, unpublished observations).

Body weight and body-mass index were similar as normal SD rats before the onset of diabetes, but were decreased after the onset (Figure 6(C)) [37] [40] [41]. At the same time, blood insulin was diminished rapidly (Figure 6(D)) [42] [43]. Therefore, the hyperglycemia of SDT rat developed insulin dependently. mRNA expressions of glucokinase and glycogen content in the liver were reduced in SDT rats at 16 weeks of age, suggesting that glucose metabolism in the liver is already disturbed before the onset of diabetes. After the onset, mRNA levels of gluconeogenesis enzymes, such as phosphoenolpyruvate carboxykinase (PEPCK), fructose-1,6-bisphosphatase (FBPase), and G6Pase, were elevated [44] [45]. 
SDT rats also developed dyslipidemia at 30 weeks of age and thereafter (Table 2) [37] [46]. Blood TG and total cholesterol (TC) levels increased after the onset of diabetes. However, in male SDT rats, the blood TG levels after fat-loading have already been high with normal TG absorption from the small intestine before the onset, suggesting that the TG clearance is already impaired. Increased TG absorption due to physical increase in TG inflow associated with polyhagia-induced hypertrophy of the small intestine occured after the onset of diabetes. Active ghrelin production, an orexigenic hormone, and suppression of insulin and leptin may be concerned with diabetic polyphagia in SDT rats [47]. In addition, enzymes involving in TG absorption in the small intestine increased in SDT rats [44] [46].

\subsection{Impaired Glucose Tolerance and Pancreatic Lesions}

The SDT rat is a good model of impaired glucose tolerance (IGT). Before 16-18 weeks of age, basal blood glucose levels in SDT rats were same as normal rats, means they do not develop diabetes at these points. However, after glucose-loading, insulin secretion decreased and blood glucose levels significantly increased (Figure 7(A) and Figure 7(B)). Glucose tolerance in SDT rats markedly decreased at least 2 months before the development of hyperglycemia and it got worse with age. After the onset of diabetes, insulin secretion disappeared and the increase of blood glucose levels was clearer (Figure $7(C)$ and Figure 7(D)) [41] [48] [49]. This blood glucose change in SDT rats at 24 weeks of age was similar to that of STZ-induced diabetes rats (Figure 7(E) and Figure $7(F)$ ). Thus SDT rats after developing diabetes and STZ-induced diabetes rats are unsuitable model of IGT.

Table 2. Comparison of blood parameters, body weight, and food consumption of SD rat and SDT rat.

\begin{tabular}{ccccc}
\hline & \multicolumn{2}{c}{ 8 weeks-old } & \multicolumn{2}{c}{ 30 weeks-old } \\
\cline { 2 - 5 } & SD rat & SDT rat & SD rat & SDT rat \\
\hline Body weight $(\mathrm{g})$ & $319.0 \pm 1.2$ & $320.5 \pm 11.2$ & $649.4 \pm 18.1$ & $469.7 \pm 7.6^{* *}$ \\
Glucose $(\mathrm{mg} / \mathrm{dl})$ & $138.7 \pm 2.2$ & $138.2 \pm 2.5$ & $119.6 \pm 1.4$ & $686.2 \pm 36.4^{\star *}$ \\
Insulin $(\mathrm{ng} / \mathrm{ml})$ & $1.41 \pm 0.40$ & $1.65 \pm 0.22$ & $1.61 \pm 0.57$ & $0.23 \pm 0.01^{*}$ \\
NEFA $(\mathrm{mEq} / \mathrm{ml})$ & $0.49 \pm 0.14$ & $0.49 \pm 0.14$ & $0.56 \pm 0.21$ & $0.76 \pm 0.36$ \\
TG $(\mathrm{mg} / \mathrm{dl})$ & $155.0 \pm 8.0$ & $168.3 \pm 36.3$ & $148.8 \pm 15.1$ & $478.1 \pm 155.0^{* *}$ \\
TC $(\mathrm{mg} / \mathrm{dl})$ & $80.4 \pm 3.9$ & $83.9 \pm 1.2$ & $114.5 \pm 9.3$ & $132.2 \pm 7.7$ \\
HDL-C (mg/dl) & $60.3 \pm 5.0$ & $63.0 \pm 1.2$ & $91.6 \pm 10.8$ & $62.6 \pm 2.7^{* *}$ \\
Non HDL-C (mg/dl) & $20.5 \pm 1.9$ & $20.5 \pm 0.4$ & $22.8 \pm 2.3$ & $69.6 \pm 22.4^{\star *}$ \\
Food consumption(g/day) & $25.2 \pm 0.9$ & $24.6 \pm 0.5$ & $22.6 \pm 1.5$ & $48.3 \pm 3.8^{* *}$ \\
Leptin (ng/ml) & $4.3 \pm 0.2$ & $4.3 \pm 0.2$ & $17.4 \pm 2.0$ & $0.4 \pm 0.1^{* *}$ \\
\hline
\end{tabular}

Biochemical parameters of non-fasted SD and SDT rats were measured at both 8 and 30 weeks of age. Each value represents mean \pm SEM $(\mathrm{n}=5-9) .{ }^{\star} \mathrm{P}<0.05,{ }^{* *} \mathrm{P}<0.01$ (vs. age-matched SD rats, unpaired $t$-test). Table is modified from Sasase et al., 2007 [46]. 
SDT (13 wk)

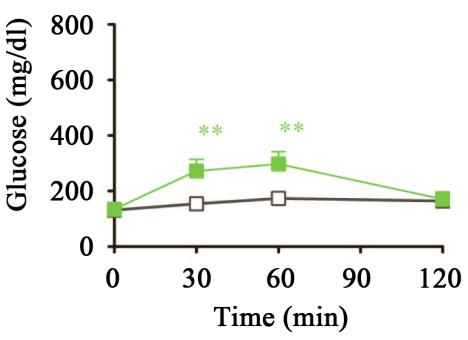

(A)

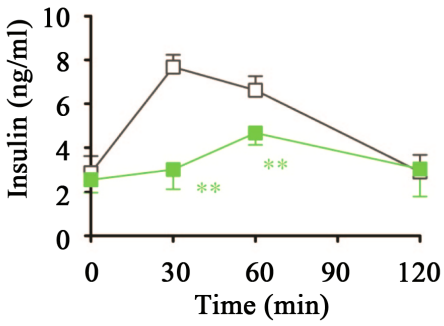

(B)
SDT (24 wk)

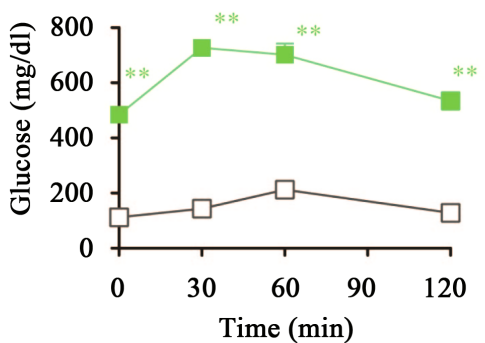

(C)

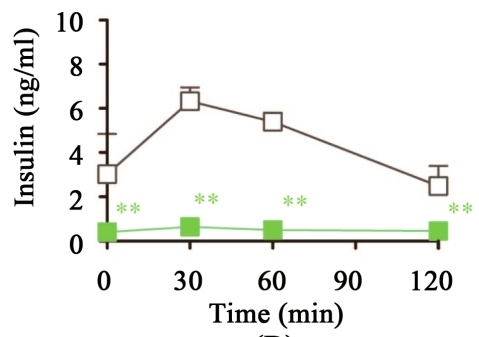

(D)
STZ (2 wk)

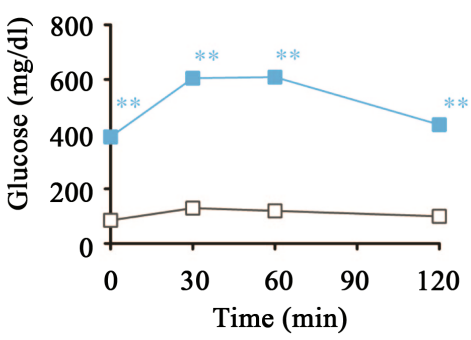

(E)

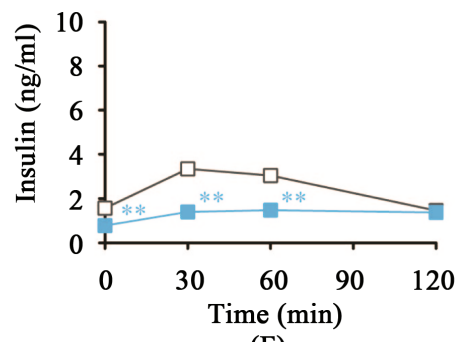

(F)

Figure 7. Changes in plasma glucose and insulin concentrations during oral glucose tolerance test (OGTT; 2 g/kg). At 13 weeks of age, SDT rats were non-diabetic but the marked elevation of plasma glucose and lower insulin concentration were observed after glucose-loading (impaired glucose tolerance; IGT) ((A), (B)). At 24 weeks of age, SDT rats become diabetic and show further elevation of plasma glucose level because of diminished insulin secretion ((C), (D)). STZ-induced diabetic rat show similar blood glucose changes as 24 weeks-old-SDT rat even at 2 weeks after STZ treatment ((E), (F)). White square; male SD rats, green square; male SDT rats, blue square; STZ-induced diabetic rats. Data represent means \pm standard deviation $(\mathrm{n}=6) .{ }^{*} \mathrm{P}<0.01$; significantly different from the control SD rat. (A) - (D) are modified from [41] [48].

In addition, in vitro study showed that the insulin secretion after glucose treatment in isolated pancreatic $\beta$-cells from SDT rats markedly decreased at 12 weeks of age compared with normal SD rats [50]. In female rats, glucose tolerance also decreased at 25 weeks of age without insulin diminution, suggesting involvement of some factors in insulin resistance in the females SDT rats [51]. It has also been reported that increased insulin secretion from hypertrophic pancreatic islets delayed the onset of hyperglycemia in SDT rats fed a high-fat diet [52].

At 8 weeks of age, microcapillary extension and congestion were frequently observed in pancreatic islets in SDT rats (Figure $8(\mathrm{~A})$ ). At 10 weeks of age, the number of pancreatic islets and the area of $\beta$-cells gradually decreased. Hemorrhages were also observed in pancreas (Figure $8(B)$ ). Inflammation and fibrosis in or around the pancreatic islets extended, and fibrosis, hemosiderin deposition, and marked decrease in $\beta$-cells were observed in almost all pancreatic islets at 20 weeks of age (Figure $8(\mathrm{C})$ and Figure $8(\mathrm{E})$ ). After development of diabetes, atrophy of pancreatic islets occupied by collagenous fibers and virtual disappearance of $\beta$-cells were observed (Figure 8(D) and Figure 8(F)) [35] [37] [41]. Such changes in pancreatic islets starting from hemorrhage were found in female SDT rats [51]. These pancreatic damages were considered as results of transient increase of IL-18 concentration and the local macrophage infiltration 
16 wk

8 wk

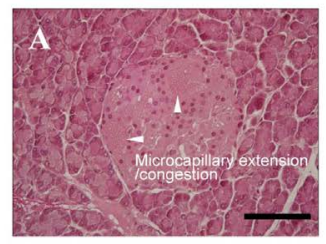

$10 \mathrm{wk}$

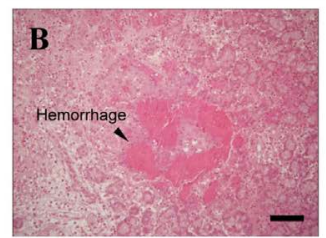

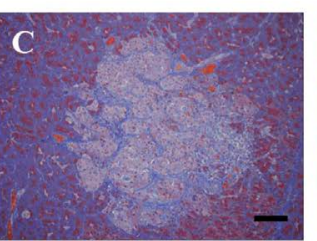

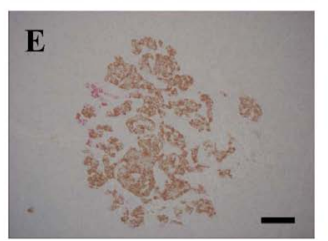

38 wk
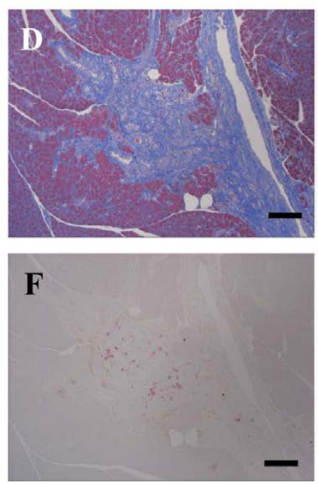

Figure 8. Histopathological observations in pancreas (islet) of SDT rats. Congestion or microcapillary extension (A) and hemorrhage (B) in the pancreatic islets were observed (HE stain). Replacement of islet cells by connective tissues with advanced fibrosis ( $(\mathrm{C})$, (D)) (MT stain). Immunohistochemistry of islet showed almost all of the $\beta$-cells (brown, insulin-immunoreactive) disappeared from the islets, whereas $\alpha$-cells (pink, glucagon-immunoreactive) were still observed at 38 weeks of age ((E), (F)). Bar $=100 \mu \mathrm{m}$. Figures are modified from [41].

[53] [54]. Weakness of pancreas in SDT rats was also suggested by higher sensitivity to STZ [43].

\subsection{Diabetic Complications}

Long-term duration of diabetes can cause severe microvascular complications such as diabetic retinopathy, diabetic nephropathy, or diabetic peripheral neuropathy. In the eye, retinopathy, cataract, and neovascular glaucoma (hemorrhagic glaucoma) are the clinically important complications. Proliferative retinopathy with tractional retinal detachment was found in some aged SDT rats. Vitreous hemorrhage and fibrovascular membrane were resulting from retinal neovascular vessels (Figure $9(\mathrm{~A})$ ). Capillary narrowing and pericyte loss were also found, but capillary aneurysms that are frequently observed in human diabetic retinopathy was not found in SDT rats (Figure 9(B)). Severe fluorescein leakage (Figure $9(\mathrm{C})$ and Figure $9(\mathrm{D})$ ) and abnormal retinal vasodilatation that may correspond to venous beading in human retinopathy was observed [35] [37] [55] [56] [57] [58] [59]. At 44 weeks of age, ERG revealed delay and reduction of oscillatory potentials (OPs) and a- and b-waves [58] [60], as is the case with human diabetic retinopathy. Kakehashi et al. [57] reported that the prevalence of diabetic retinopathy was $8 \%$ at 35 to 50 weeks of age, but was increased to approximately $80 \%$ at 51 to 60 weeks and finally reached $100 \%$ at 61 to 82 weeks. Increased expression of vascular endothelial growth factor (VEGF) is deeply involved in angiogenesis as in human diabetic retinopathy. Gene therapy with soluble VEGF receptor (sFlt-1) into the retina prevented fluorescein leakage from the retina at 57 weeks of age SDT rat [61] [62]. In some severe human diabetic retinopathy, excess VEGF produced by advanced retinal ischemia develops angiogenesis in the iris or anterior chamber angle to cause neovascular glaucoma, 

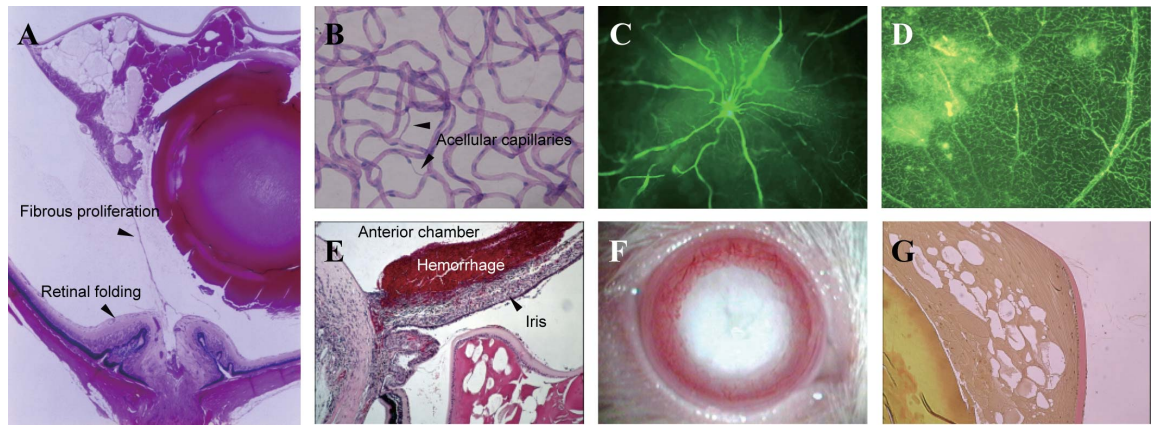

Figure 9. Typical ocular observations in SDT rats. Large retinal folds were seen in the midperipheral retina and around the optic disk. A tractional retinal detachment was observed with fibrous proliferation (A) (HE stain); Retinal trypsin digestion showed acellular capillaries (B) (HE stain); Tortuous vessels and extensive fluorescein leakages were observed in retinal flat mounts from SDT rats ((C), (D)); Massive hemorrhage in the anterior chamber associated with proliferation around the iris was seen in some severe case (E) (HE stain); The mature cataract was observed clearly in the dilated pupil (F); The sclerotic nucleus floats in a liquefied lens cortex. Vacuolation, disintegration of the lens fibers, and Morgani's globules were observed in the lens cortex $(G)$ (Elastica van Gieson stain). Figures are modified from [37] [55] [57] [58] [59].

one of the most severe ocular complications. Currently, there is no animal models show neovascular glaucoma. SDT rats with advanced retinopathy developed fibrovascular membrane around the iris and sometimes with anterior chamber hemorrhage (Figure 9(E)) [35] [37] [55] [57]. Although there is no report that evaluates ocular pressure, SDT rat may have potential to be a model of neovascular glaucoma. After 40 weeks of age, male SDT rats showed opacity at the posterior pole of the lens and finally developed hypermature cataract (Figure $9(F)$ and Figure $9(G)$ ). Nuclear sclerosis progresses and the cortex is highly opacified. Swollen of lens fibers, liquefaction, vacuolation, abnormal configuration, and formation of Morgagnian droplets, and partial proliferation of fibroblastoid cells were found pathologically [35] [37] [55] [56] [57] [58] [59]. Controlling blood glucose level with long-term insulin treatment or pancreas transplantation prevented all these ocular abnormalities. Therefore these ocular complications are considered accompanied by sustained hyperglycemia [58] [63].

Some renal lesions were found in SDT rats at 24 weeks of age, such as thickening of the glomerular loop, glycogen deposition in the tubular epithelium (Armanni-Ebstein lesion), dilatation of the renal tubule lumen, and increased hyaline casts. Slight thickening of the glomerular loop was consistent with mesangial proliferation, Masson's trichrome stain, and type IV collagen immunostaining (Figures 10(A)-(F)). Mesangial proliferation developed with age, and nodular lesions (Kimmelstiel-Wilson-like nodules) that suggest more severe glomerular lesions were slightly observed at 68 weeks of age (Figure $10(\mathrm{G})$ ). The renal tubular lesions also increased with a marked increase in tubular glycogen deposition at 50 and 68 weeks of age (Figure 10(H)). In addition, urine volume, urine protein, and urine albumin increased with blood glucose at 24 weeks of age and thereafter, and these changes may be consistent with the development of 
PAS

SD

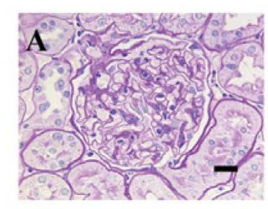

SDT

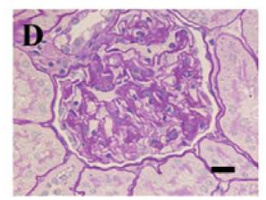

MT
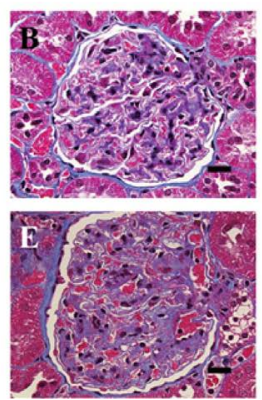

Collagen IV
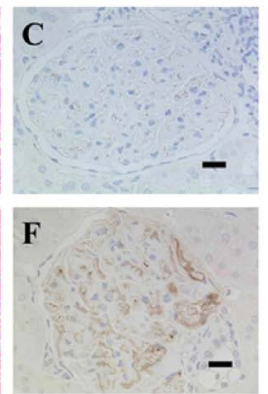
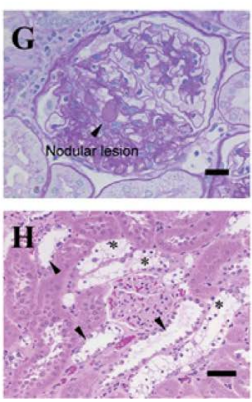

Figure 10. Histological and immunohistological analysis of glomeruli in SD rats ((A) (C)) and SDT rats ((D) - (F)). In the glomeruli of SDT rats, basement membrane thickening and mesangial matrix proliferation were observed at 50 weeks of age (Bar $=20 \mu \mathrm{m})$. Nodular lesions were found in a few glomeruli from 68-weeks-old SDT rats (G) (PAS stain, Bar $=20 \mu \mathrm{m}$ ). In the renal tubules of SDT rats, dilation (arrowhead) and glycogen deposition in the epithelium $\left(^{*}\right)$ were observed $(\mathrm{H})(\mathrm{HE}$ stain, Bar $=50 \mu \mathrm{m})$. Figures are modified from [65].

renal lesions [64] [65]. These renal lesions were also improved by blood glucose control with insulin and thus shown to result from exposure to high blood glucose [64] [65]. The blood asymmetric dimethylarginine (ADMA) concentration, urinary excretion of oxidative stress markers 8-hydroxydeoxyguanosine (8-OHdG), and nitrogen oxide (NOx) increased in SDT rats at 36 weeks of age. In addition, glomerular hypertrophy and mesangial proliferation were found pathologically. From immunohistopathological study, increase of glomerular 8-OHdG, endothelial NO synthase (eNOS), and nitrothyrosine were also reported. These findings indicated an important role of oxidative stress on the progression of diabetic nephropathy [66] [67].

In diabetic peripheral neuropathy (DPN), both motor and sensory nerves are impaired. In an electrophysiological and morphological study, the MNCV and sensory nerve conduction velocity (SNCV) in SDT rats were same as in normal SD rats until 6 months of age, but gradually decreased to less than $80 \%$ of that in normal SD rats at 12 months (Figure 11(A)). Increased nerve sorbitol and fructose contents and decreased myo-inositol contents in SDT rats indicated that the polyol pathway was prominently involved in DPN [68] [69]. Neurologic deficit was not observed in the sural nerve cross-section, but degenerated nerves increased in SDT rats. The myelinated nerve area in SDT rats was not clearly different from normal rats at 6 months of age, but decreased at 12 months compared with normal rats. Morphologically, the number of blood vessels in the nerve sheath was not clearly different; however, occluded/thickened epineurial arterioles were observed in SDT rats (Figures 11(B)-(E)). Thickened intima disturbs nerve perfusion and accelerates DPN. Therefore, SDT rats developed peripheral neuropathy associated with type 2 diabetese, including functional/morphological abnormalities of peripheral nerves and vascular lesions [68] [69]. Autonomic nerve is part of the peripheral nervous system and transmits impulses from the central nervous system to peripheral organ systems. Diabetic 
A

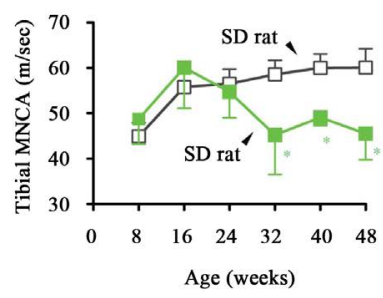

SD

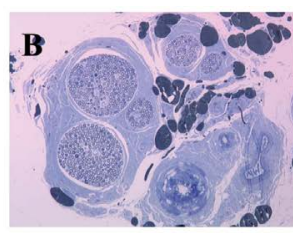

SDT

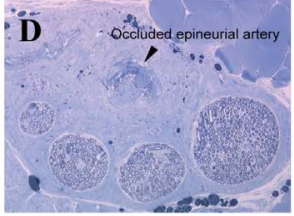

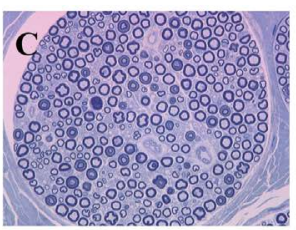

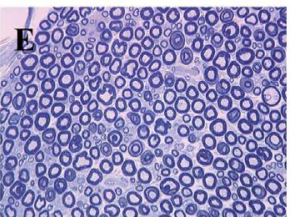

Figure 11. Diabetic peripheral neuropathy and histopathology in sural nerves of SDT rats. Serial changes of tibial motor nerve conduction velocity (MNCV) in male SD rats (white square) and male SDT rats (green square) (A). MNCV reduced after the onset of diabetes. Data represent means \pm standard deviation $(n=6)$. ${ }^{\star} \mathrm{P}<0.05$; significantly different from the control SD rat. Morphologically, SDT rats revealed significant atrophy in myelinated nerve at 48 weeks of age. Occluded/thickened epineurial arterioles were found in SDT rats. Typical low ((B), (D)) and high ((C), (E)) magnification microphotographs of sural nerves from SD rat and SDT rat (toluidine blue stain). Figures are modified from [68].

autonomic nerve dysfunction was also evidenced in SDT rats. Diabetic diarrhea and increased gastrointestinal motility with higher fecal water content were observed in SDT rats [70]. In a study of voiding function, voiding pressure, voided volume per micturition, and inter-micturition interval tended to increase in SDT rats [71].

At 36 weeks of age, bone formation and resorption decreased in SDT rats compared with normal SD rats. Bone density and strength also decreased in SDT rats (Figure 12). As a result of mechanical stress test, energy absorption significantly decreased in SDT rat, indicating decrease of bone strength. Decreased bone density and low-turnover bone lesions are found as seen with type 2 diabetes primarily due to decreased insulin secretion. Actually, the diabetic osteoporosis was improved with insulin treatment, indicating involvement of insulin on bone metabolism [72] [73].

\subsection{Pharmacological Study}

Use of animal models is essential to development of diabetes drugs. Currently, SDT rats are used for development and application of several diabetes drugs. In addition to insulin treatment [58] [65], sulfonylurea (tolbutamide) and DPP IV inhibitor (JTP-76209) [50], $\alpha$-glucosidase inhibitor (voglibose) [74], SGLT inhibitor (phlorizin) [44] [49], and perilla (shiso) tea [75] were treated to SDT rats to control blood glucose levels. Diabetic microangiopathy was reportedly caused by increased tissue protein kinase C-beta (PKC $\beta$ ) activity at high blood glucose levels. Twelve week-treatment of a PKC $\beta$ inhibitor JTT-010 improved retinal dysfunction such as delayed OPs in ERG, neuropathy such as decreased caudal $\mathrm{MNCV}$, electrocardiographic coefficient of variation of R-R interval $\left(\mathrm{CV}_{\mathrm{R}-\mathrm{R}}\right)$, and thermal hypoalgesia in diabetic SDT rats [76]. Also, a transketolase activator benfotiamine that reduces major pathways related to diabetic microvascular 


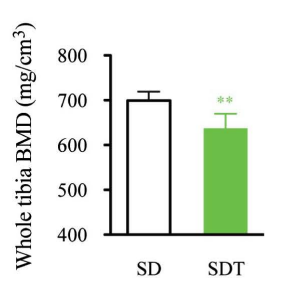

(A)

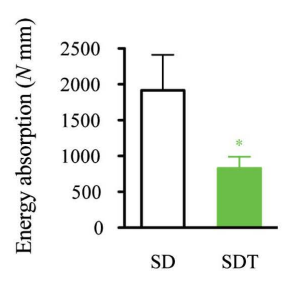

(B)

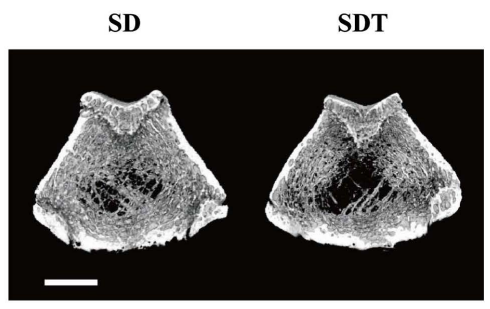

(C)

Figure 12. Bone properties (osteoporosis) of SDT rats. Bone mineral density (BMD) of the whole tibia (A) and mechanical property of the femur midshaft (B) were clearly indicating diabetes-induced osteoporosis in SDT rats. White column; male SD rats, green column; male SDT rats (40 weeks of age). Data represent means \pm standard deviation (n $=5) .{ }^{\star} \mathrm{P}<0.01,{ }^{\star} \mathrm{P}<0.05$; significantly different from the control SD rats. The reconstructed bone microstructure 3D images of femur from 40 weeks SDT rats showed the obvious bone loss $(\mathrm{C})(\mathrm{Bar}=2 \mathrm{~mm})$. Figures are modified from [73].

complications, such as polyol pathway, hexosamine pathway, advanced glycation end product (AGE) pathway, and diacylglycerol (DAG)-PKC pathway, showed preventive effects on peripheral nerve dysfunction in SDT rats [68]. An angiotensin II type 1 receptor blockers (ARBs) are known to inhibit the development of retinopathy in type 2 diabetes patients [77]. In SDT rats, blood glucose level was not controlled by telmisartan, but blood pressure decreased; delayed OPs and a-wave in ERG were improved and fluorescein leakage from retinal vasculature in SDT rats was inhibited, suggesting that the ARB may suppress the development of proliferative retinopathy in SDT rats [78]. In addition, candesartan decreased the pentosidine content in the lens/vitreous body in SDT rats, and the drug inhibited accumulation of pentosidine in the retinal vascular wall and decreased retinal VEGF mRNA expression [79]. These findings indicated that ARBs can suppress the development of proliferative diabetic retinopathy by inhibiting AGE formation. Furthermore, cataract and retinopathy in SDT rats were reportedly prevented by aldose reductase inhibitors, fidarestat [80] and ranirest [81], AGE inhibitor aminoguanidine [82], and $\alpha 1 / \beta$ blocker nipradilol [83].

\section{Conclusion}

The GK rat is a non-obese type 2 diabetic rat, showing impaired glucose tolerance and sustained hyperglycemia with a reduction of GSIS. In particular, the reduction of the first phase in GSIS is an important property, and a similar change is also found in type 2 diabetes in humans. With sustained hyperglycemia, diabetic complications, including nephropathy and neuropathy, are shown in GK rats. GK rats have contributed to development of anti-diabetic drugs. The SDT rat shows ocular complications similar to those in human diabetes, and severe diabetic neuropathy and nephropathy are caused by long-term hyperglycemia. Also, SDT rats show IGT before they develop diabetes. The diabetic rat models have played an important role in elucidating the pathogenesis of human 
type 2 diabetes and developing the new anti-diabetic drugs. In the future, the diabetic rat models may be necessary for developing of new therapies in Unmet Medical Needs for diabetic complications.

\section{Conflicts of Interest}

TO and TS are employees of Japan Tobacco Inc. TG and MS are employee of CLEA Japan Inc. PS, SF, RT, and TK are employees of Nomura Siam International Co., Ltd.

\section{References}

[1] King, H., Aubert, R.E. and Herman, W.H. (1998) Global Burden of Diabetes, 1995-2025: Prevalence, Numerical Estimates, and Projections. Diabetes Care, 21, 1414-1431. https://doi.org/10.2337/diacare.21.9.1414

[2] Yoon, K.H., Lee, J.H., Kim, J.W., Cho, J.H., Choi, Y.H., Ko, S.H., Zimmet, P. and Son, H.Y. (2006) Epidemic Obesity and Type 2 Diabetes in Asia. The Lancet, 368, 1681-1688. https://doi.org/10.1016/S0140-6736(06)69703-1

[3] Szoke, E., Shrayyef, M.Z., Messing, S., Woerle, H.J., van Haeften, T.W., Meyer, C., Mitrakou, A., Pimenta, W. and Gerich, J.E. (2008) Effect of Aging on Glucose Homeostasis: Accelerated Deterioration of $\beta$-Cell Function in Individuals with Impaired Glucose Tolerance. Diabetes Care, 31, 539-543. https://doi.org/10.2337/dc07-1443

[4] Ritz, E. and Stefanski, A. (1996) Diabetic Nephropathy in Type II Diabetes. American Journal of Kidney Diseases, 27, 167-194. https://doi.org/10.1016/S0272-6386(96)90538-7

[5] Hall, J.E., Kuo, J.J., da Silva, A.A., de Paula, R.B., Liu, J. and Tallam, L. (2003) Obesity-Associated Hypertension and Kidney Disease. Current Opinion in Nephrology and Hypertension, 12, 195-200. https://doi.org/10.1097/00041552-200303000-00011

[6] Cortez, M., Singleton, J.R. and Smith, A.G. (2014) Glucose Intolerance, Metabolic Syndrome, and Neuropathy. Handbook of Clinical Neurology, 126, 109-122. https://doi.org/10.1016/B978-0-444-53480-4.00009-6

[7] Calcutt, N.A., Cooper, M.E., Kern, T.S. and Schmidt, A.M. (2009) Therapies for Hyperglycaemia-Induced Diabetic Complications: From Animal Models to Clinical Trials. Nature Reviews Drug Discovery, 8, 417-429. https://doi.org/10.1038/nrd2476

[8] Brown, A., Guess, N., Dornhorst, A., Taheri, S. and Frost, G. (2017) Insulin-Associated Weight Gain in Obese Type 2 Diabetes Mellitus Patients: What Can Be Done? Diabetes, Obesity and Metabolism, 19, 1655-1668. https://doi.org/10.1111/dom.13009

[9] Kawano, K., Hirashima, T., Mori, S., Saitoh, Y., Kurosumi, M. and Natori, T. (1992) Spontaneous Long-Term Hyperglycemic Rat with Diabetic Complications. Otsuka Long-Evans Tokushima Fatty (OLETF) Strain. Diabetes, 41, 1422-1428. https://doi.org/10.2337/diab.41.11.1422

[10] Portha, B., Picon, L. and Rosselin, G. (1979) Chemical Diabetes in the Adult Rat as the Spontaneous Evolution of Neonatal Diabetes. Diabetologia, 17, 371-377. https://doi.org/10.1007/BF01236272

[11] Weir, G.C., Clore, E.T., Zmachinski, C.J. and Bonner-Weir, S. (1981) Islet Secretion in a New Experimental Model for Non-Insulin-Dependent Diabetes. Diabetes, 30, 590-595. https://doi.org/10.2337/diab.30.7.590

[12] Giroix, M.H., Portha, B., Kergoat, M., Bailbe, D. and Picon, L. (1983) Glucose In- 
sensitivity and Amino-Acid Hypersensitivity of Insulin Release in Rats with Non-Insulin-Dependent Diabetes. A Study with the Perfused Pancreas. Diabetes, 32, 445-451. https://doi.org/10.2337/diab.32.5.445

[13] Goto, Y., Kakizaki, M. and Masaki, N. (1976) Production of Spontaneous Diabetic rats by Repetition of Selective Breeding. The Tohoku Journal of Experimental Medicine, 119, 85-90. https://doi.org/10.1620/tjem.119.85

[14] Galli, J., Li, L.S., Glaser, A., Ostenson, C.G., Jiao, H., Fakhrai-Rad, H., Jacob, H.J., Lander, E.S. and Luthman, H. (1996) Genetic Analysis of Non-Insulin Dependent Diabetes Mellitus in the GK Rat. Nature Genetics, 12, 31-37. https://doi.org/10.1038/ng0196-31

[15] Gauguier, D., Froguel, P., Parent, V., Bernard, C., Bihoreau, M.T., Portha, B., James, M.R., Penicaud, L., Lathrop, M. and Ktorza, A. (1996) Chromosomal Mapping of Genetic Loci Associated with Non-Insulin Dependent Diabetes in the GK Rat. Nature Genetics, 12, 38-43. https://doi.org/10.1038/ng0196-38

[16] Kimura, K., Toyota, T., Kakizaki, M., Kudo, M., Takebe, K. and Goto, Y. (1982) Impaired Insulin Secretion in the Spontaneous Diabetes Rats. The Tohoku Journal of Experimental Medicine, 137, 453-459. https://doi.org/10.1620/tjem.137.453

[17] Tsuura, Y., Ishida, H., Okamoto, Y., Kato, S., Sakamoto, K., Horie, M., Ikeda, H., Okada, Y. and Seino, Y. (1993) Glucose Sensitivity of ATP-Sensitive $\mathrm{K}^{+}$Channels Is Impaired in Beta-Cells of the GK Rat. A New Genetic Model of NIDDM. Diabetes, 42, 1446-1453. https://doi.org/10.2337/diab.42.10.1446

[18] Villar-Palasi, C. and Farese, R.V. (1994) Impaired Skeletal Muscle Glycogen Synthase Activation by Insulin in the Goto-Kakizaki (G/K) Rat. Diabetologia, 37, 885-888. https://doi.org/10.1007/BF00400943

[19] Kitahara, A., Toyota, T., Kakizaki, M. and Goto, Y. (1978) Activities of Hepatic Enzymes in Spontaneous Diabetes Rats Produced by Selective Breeding of Normal Wistar Rats. The Tohoku Journal of Experimental Medicine, 126, 7-11. https://doi.org/10.1620/tjem.126.7

[20] Belfiore, F., Romeo, F., Napoli, E. and Lo Vecchio, L. (1974) Enzymes of Glucose Metabolism in Liver of Subjects with Adult-Onset Diabetes. Diabetes, 23, 293-301. https://doi.org/10.2337/diab.23.4.293

[21] Yagihashi, S., Tonosaki, A., Yamada, K., Kakizaki, M. and Goto, Y. (1982) Peripheral Neuropathy in Selectively-Inbred Spontaneously Diabetic Rats: Electrophysiological, Morphometrical and Freeze-Replica Studies. The Tohoku Journal of Experimental Medicine, 138, 39-48. https://doi.org/10.1620/tjem.138.39

[22] Kinoshita, J.H., Futterman, S., Satoh, K. and Merola, L.O. (1963) Factors Affecting the Formation of Sugar Alcohols in Ocular Lens. Biochimica et Biophysica Acta, 74, 340-350. https://doi.org/10.1016/0006-3002(63)91377-5

[23] Greene, D.A., Lattimer, S.A. and Sima, A.A. (1987) Sorbitol, Phosphoinositides, and Sodium-Potassium-ATPase in the Pathogenesis of Diabetic Complications. The New England Journal of Medicine, 316, 599-606. https://doi.org/10.1056/NEJM198703053161007

[24] Schrijvers, B.F., De Vriese, A.S., Van de Voorde, J., Rasch, R., Lameire, N.H. and Flyvbjerg, A. (2004) Long-Term Renal Changes in the Goto-Kakizaki Rat, a Model of Lean Type 2 Diabetes. Nephrology Dialysis Transplantation, 19, 1092-1097. https://doi.org/10.1093/ndt/gfh107

[25] Yagihashi, S., Kaseda, N., Kakizaki, M. and Goto, Y. (1979) Evolution of Glomerular Lesions in Rats with Spontaneous Diabetes. The Tohoku Journal of Experimental Medicine, 127, 359-367. https://doi.org/10.1620/tjem.127.359 
[26] Phillips, A.O., Baboolal, K., Riley, S., Grone, H., Janssen, U., Steadman, R., Williams, J. and Floege, J. (2001) Association of Prolonged Hyperglycemia with Glomerular Hypertrophy and Renal Basement Membrane Thickening in the Goto Kakizaki Model of Non-Insulin-Dependent Diabetes Mellitus. American Journal of Kidney Diseases, 37, 400-410. https://doi.org/10.1053/ajkd.2001.21322

[27] Miyamoto, K., Ogura, Y., Nishiwaki, H., Matsuda, N., Honda, Y., Kato, S., Ishida, H. and Seino, Y. (1996) Evaluation of Retinal Microcirculatory Alterations in the Goto-Kakizaki Rat. A Spontaneous Model of Non-Insulin-Dependent Diabetes. Investigative Ophthalmology \& Visual Science, 37, 898-905.

[28] Agardh, C.D., Agardh, E., Zhang, H. and Ostenson, C.G. (1997) Altered Endothelial/Pericyte Ratio in Goto-Kakizaki Rat Retina. Journal of Diabetes and Its Complications, 11, 158-162. https://doi.org/10.1016/S1056-8727(96)00049-9

[29] Matsubara, H., Kuze, M., Sasoh, M., Ma, N., Furuta, M. and Uji, Y. (2006) Time-Dependent Course of Electroretinograms in the Spontaneous Diabetic Goto-Kakizaki Rat. Japanese Journal of Ophthalmology, 50, 211-216. https://doi.org/10.1007/s10384-005-0315-8

[30] Ohta, T., Furukawa, N., Komuro, G., Yonemori, F. and Wakitani, K. (1999) JTT-608 Restores Impaired Early Insulin Secretion in Diabetic Goto-Kakizaki Rats. British Journal of Pharmacology, 126, 1674-1680. https://doi.org/10.1038/sj.bjp.0702481

[31] Ohta, T., Miyajima, K., Komuro, G., Furukawa, N. and Yonemori, F. (2003) Antidiabetic Effect of Chronic Administration of JTT-608, a New Hypoglycemic Agent, in Diabetic Goto-Kakizaki Rats. European Journal of Pharmacology, 476, 159-166. https://doi.org/10.1016/S0014-2999(03)02120-4

[32] Inaba, W., Mizukami, H., Kamata, K., Takahashi, K., Tsuboi, K. and Yagihashi, S. (2012) Effects of Long-Term Treatment with the Dipeptidyl Peptidase-4 Inhibitor Vildagliptin on Islet Endocrine Cells in Non-Obese Type 2 Diabetic Goto-Kakizaki Rats. European Journal of Pharmacology, 691, 297-306. https://doi.org/10.1016/j.ejphar.2012.07.030

[33] Mizukami, H., Inaba, W., Takahashi, K., Kamata, K., Tsuboi, K. and Yagihashi, S. (2013) The Effects of Dipeptidyl-Peptidase-IV Inhibitor, Vildagliptin, on the Exocrine Pancreas in Spontaneously Diabetic Goto-Kakizaki Rats. Pancreas, 42, 786-794. https://doi.org/10.1097/MPA.0b013e318287c9b5

[34] Ueta, K., Ishihara, T., Matsumoto, Y., Oku, A., Nawano, M., Fujita, T., Saito, A. and Arakawa, K. (2005) Long-Term Treatment with the $\mathrm{Na}^{+}$-glucose Cotransporter Inhibitor T-1095 Causes Sustained Improvement in Hyperglycemia and Prevents Diabetic Neuropathy in Goto-Kakizaki Rats. Life Sciences, 76, 2655-2668.

https://doi.org/10.1016/j.lfs.2004.09.038

[35] Shinohara, M., Masuyama, T. and Kakehashi, A. (2007) The Spontaneously Diabetic Torii (SDT) Rat with Retinopathy Lesions Resembling Those of Humans. In: Shafrir, E., Ed., Animal Models of Diabetes: Frontiers in Research, CRC Press, Boca Raton, 311-322.

[36] Shinohara, M., Oikawa, T., Sato, K. and Kanazawa, M. (2011) Effect of Oophorectomy and Estrogen Administration on Diabetic Pathogenesis in Female Spontaneously Diabetic Torii Rats. The Open Diabetes Journal, 4, 96-100. https://doi.org/10.2174/1876524601104010096

[37] Shinohara, M., Masuyama, T., Shoda, T., Takahashi, T., Katsuda, Y., Komeda, K., Kuroki, M., Kakehashi, A. and Kanazawa, Y. (2000) A New Spontaneously Diabetic Non-Obese Torii Rat Strain with Severe Ocular Complications. International Jour- 
nal of Experimental Diabetes Research, 1, 89-100. https://doi.org/10.1155/EDR.2000.89

[38] Masuyama, T., Fuse, M., Yokoi, N., Shinohara, M., Tsujii, H., Kanazawa, M., Kanazawa, Y., Komeda, K. and Taniguchi, K. (2003) Genetic Analysis for Diabetes in a New Rat Model of Nonobese Type 2 Diabetes, Spontaneously Diabetic Torii Rat. Biochemical and Biophysical Research Communications, 304, 196-206. https://doi.org/10.1016/S0006-291X(03)00548-5

[39] Fuse, M., Yokoi, N., Shinohara, M., Masuyama, T., Kitazawa, R., Kitazawa, S. and Seino, S. (2008) Identification of a Major Locus for Islet Inflammation and Fibrosis in the Spontaneously Diabetic Torii Rat. Physiological Genomics, 35, 96-105. https://doi.org/10.1152/physiolgenomics.90214.2008

[40] Masuyama, T. (2011) Characteristics of Diabetes in the SDT Rat. The Open Diabetes Journal, 4, 26-29. https://doi.org/10.2174/1876524601104010026

[41] Masuyama, T., Komeda, K., Hara, A., Noda, M., Shinohara, M., Oikawa, T., Kanazawa, Y. and Taniguchi, K. (2004) Chronological Characterization of Diabetes Development in Male Spontaneously Diabetic Torii Rats. Biochemical and Biophysical Research Communications, 314, 870-877. https://doi.org/10.1016/j.bbrc.2003.12.180

[42] Masuyama, T., Katsuda, Y. and Shinohara, M. (2005) A Novel Model of Obesity-Related Diabetes: Introgression of the Lepr(fa) Allele of the Zucker Fatty Rat into Nonobese Spontaneously Diabetic Torii (SDT) Rats. Experimental Animals, 54, 13-20. https://doi.org/10.1538/expanim.54.13

[43] Ohta, T., Miyajima, K. and Yamada, T. (2011) Pathophysiological Changes in Pre-Diabetic Stage of Spontaneously Diabetic Torii (SDT) Rats. Journal of Animal and Veterinary Advances, 10, 813-817. https://doi.org/10.3923/javaa.2011.813.817

[44] Mera, Y., Morinaga, H., Ohta, T. and Sasase, T. (2011) Glucose and Lipid Metabolism in Spontaneously Diabetic Torii Rat. The Open Diabetes Journal, 4, 55-59. https://doi.org/10.2174/1876524601104010055

[45] Morinaga, H., Yamamoto, H., Sakata, K., Fukuda, S., Ito, M., Sasase, T., Miyajima, K., Ueda, N., Ohta, T. and Matsushita, M. (2008) Characterization of Hepatic Glucose Metabolism Disorder with the Progress of Diabetes in Male Spontaneously Diabetic Torii Rats. The Journal of Veterinary Medical Science, 70, 1239-1245. https://doi.org/10.1292/jvms.70.1239

[46] Sasase, T., Morinaga, H., Yamamoto, H., Ogawa, N., Matsui, K., Miyajima, K., Kawai, T., Mera, Y., Masuyama, T., Shinohara, M., Ohta, T. and Matsushita, M. (2007) Increased Fat Absorption and Impaired Fat Clearance Cause Postprandial Hypertriglyceridemia in Spontaneously Diabetic Torii Rat. Diabetes Research and Clinical Practice, 78, 8-15. https://doi.org/10.1016/j.diabres.2007.02.020

[47] Mifune, H., Nishi, Y., Tajiri, Y., Masuyama, T., Hosoda, H., Kangawa, K. and Kojima, M. (2012) Increased Production of Active Ghrelin Is Relevant to Hyperphagia in Nonobese Spontaneously Diabetic Torii Rats. Metabolism, 61, 491-495. https://doi.org/10.1016/j.metabol.2011.09.001

[48] Ishii, Y., Ohta, T. and Sasase, T. (2012) Non-Obese Type 2 Diabetes Animals Models. In: Chackrewarthy, S., Ed., Glucose Tolerance, IntechOpen, London, 223-242. https://doi.org/10.5772/52712

[49] Ohta, T., Morinaga, H., Yamamoto, T. and Yamada, T. (2012) Effect of Phlorizin on Metabolic Abnormalities in Spontaneously Diabetic Torii (SDT) Rats. Open Journal of Animal Sciences, 2, 113-118. https://doi.org/10.4236/ojas.2012.22016 
[50] Matsui, K., Oda, T., Nishizawa, E., Sano, R., Yamamoto, H., Fukuda, S., Sasase, T., Miyajima, K., Ueda, N., Ishii, Y., Ohta, T. and Matsushita, M. (2009) Pancreatic Function of Spontaneously Diabetic Torii Rats in Pre-Diabetic Stage. Experimental Animals, 58, 363-374. https://doi.org/10.1538/expanim.58.363

[51] Shinohara, M., Oikawa, T., Sato, K. and Kanazawa, Y. (2004) Glucose Intolerance and Hyperlipidemia Prior to Diabetes Onset in Female Spontaneously Diabetic Torii (SDT) Rats. Experimental Diabesity Research, 5, 253-256. https://doi.org/10.1080/15438600490898609

[52] Ishii, Y., Ohta, T., Sasase, T., Morinaga, H., Hata, T., Miyajima, K., Katusda, Y., Masuyama, T., Shinohara, M., Kakutani, M. and Matsushita, M. (2010) A High-Fat Diet Inhibits the Progression of Diabetes Mellitus in Type 2 Diabetic Rats. Nutrition Research, 30, 483-491. https://doi.org/10.1016/j.nutres.2010.06.013

[53] Inokuchi, C., Ueda, H., Hamaguchi, T., Miyagawa, J., Shinohara, M., Okamura, H. and Namba, M. (2009) Role of Macrophages in the Development of Pancreatic Islet Injury in Spontaneously Diabetic Torii Rats. Experimental Animals, 58, 383-394. https://doi.org/10.1538/expanim.58.383

[54] Mukai, E., Ohta, T., Kawamura, H., Lee, E.Y., Morita, A., Sasase, T., Miyajima, K., Inagaki, N., Iwanaga, T. and Miki, T. (2014) Enhanced Vascular Endothelial Growth Factor Signaling in Islets Contributes to Beta Cell Injury and Consequential Diabetes in Spontaneously Diabetic Torii Rats. Diabetes Research and Clinical Practice, 106, 303-311. https://doi.org/10.1016/j.diabres.2014.08.023

[55] Kakehashi, A. (2011) Diabetic Ocular Complications in the SDT Rat. The Open Diabetes Journal, 4, 37-40. https://doi.org/10.2174/1876524601104010037

[56] Shoda, T., Shinohara, M., Takahashi, T., Miyajima, K., Kakehashi, A. and Miyakawa, Y. (2007) Histopathological Features of Diabetic Ocular Complications in the Spontaneously Diabetic Torii (SDT) Rat. Journal of Toxicologic Pathology, 20, 179-183. https://doi.org/10.1293/tox.20.179

[57] Kakehashi, A., Saito, Y., Mori, K., Sugi, N., Ono, R., Yamagami, H., Shinohara, M., Tamemoto, H., Ishikawa, S.E., Kawakami, M. and Kanazawa, Y. (2006) Characteristics of Diabetic Retinopathy in SDT Rats. Diabetes/Metabolism Research and Reviews, 22, 455-461. https://doi.org/10.1002/dmrr.638

[58] Sasase, T., Ohta, T., Ogawa, N., Miyajima, K., Ito, M., Yamamoto, H., Morinaga, H. and Matsushita, M. (2006) Preventive Effects of Glycaemic Control on Ocular Complications of Spontaneously Diabetic Torii Rat. Diabetes, Obesity and Metabolism, 8, 501-507. https://doi.org/10.1111/j.1463-1326.2005.00535.x

[59] Sasase, T. (2010) Pathophysiological Characteristics of Diabetic Ocular Complications in Spontaneously Diabetic Torii Rat. Journal of Ophthalmology, 2010, Article ID: 615641. https://doi.org/10.1155/2010/615641

[60] Okuno, T., Oku, H., Sugiyama, T. and Ikeda, T. (2008) Electroretinographic Study of Spontaneously Diabetic Torii Rats. Documenta Ophthalmologica, 117, 191-196. https://doi.org/10.1007/s10633-008-9122-0

[61] Mizukami, H., Urabe, M., Kume, A. and Ozawa, K. (2011) Gene Therapy for Diabetic Retinopathy in Animal Models and Humans. The Open Diabetes Journal, 4, 119-122. https://doi.org/10.2174/1876524601104010119

[62] Ideno, J., Mizukami, H., Kakehashi, A., Saito, Y., Okada, T., Urabe, M., Kume, A., Kuroki, M., Kawakami, M., Ishibashi, S. and Ozawa, K. (2007) Prevention of Diabetic Retinopathy by Intraocular Soluble flt-1 Gene Transfer in a Spontaneously Diabetic Rat Model. International Journal of Molecular Medicine, 19, 75-79. https://doi.org/10.3892/ijmm.19.1.75 
[63] Miao, G., Ito, T., Uchikoshi, F., Kamei, M., Akamaru, Y., Kiyomoto, T., Komoda, H., Nozawa, M. and Matsuda, H. (2004) Stage-Dependent Effect of Pancreatic Transplantation on Diabetic Ocular Complications in the Spontaneously Diabetic Torii Rat. Transplantation, 77, 658-663. https://doi.org/10.1097/01.TP.0000113790.88730.41

[64] Ohta, T. and Sasase, T. (2011) Diabetic Nephropathy in Spontaneously Diabetic Torii (SDT) Rats. The Open Diabetes Journal, 4, 45-49. https://doi.org/10.2174/1876524601104010045

[65] Ohta, T., Matsui, K., Miyajima, K., Sasase, T., Masuyama, T., Shoda, T., Koizumi, H., Shinohara, M. and Matsushita, M. (2007) Effect of Insulin Therapy on Renal Changes in Spontaneously Diabetic Torii Rats. Experimental Animals, 56, 355-362. https://doi.org/10.1538/expanim.56.355

[66] Fujii, H., Kono, K., Nakai, K., Goto, S., Komaba, H., Hamada, Y., Shinohara, M., Kitazawa, R., Kitazawa, S. and Fukagawa, M. (2010) Oxidative and Nitrosative Stress and Progression of Diabetic Nephropathy in Type 2 Diabetes. American Journal of Nephrology, 31, 342-352. https://doi.org/10.1159/000297290

[67] Kim, J., Shon, E., Kim, C.S. and Kim, J.S. (2012) Renal Podocyte Injury in a Rat Model of Type 2 Diabetes Is Prevented by Metformin. Experimental Diabetes Research, 2012, Article ID: 210821. https://doi.org/10.1155/2012/210821

[68] Sasase, T. and Ohta, T. (2011) Diabetic Neuropathy in Spontaneously Diabetic Torii Rat. The Open Diabetes Journal, 4, 50-54. https://doi.org/10.2174/1876524601104010050

[69] Yamaguchi, T., Sasase, T., Mera, Y., Tomimoto, D., Tadaki, H., Kemmochi, Y., Ohta, T., Sato, E. and Matsushita, M. (2012) Diabetic Peripheral Neuropathy in Spontaneously Diabetic Torii-Lepr(fa) (SDT fatty) Rats. The Journal of Veterinary Medical Science, 74, 1669-1673. https://doi.org/10.1292/jvms.12-0149

[70] Yamada, K., Hosokawa, M., Fujimoto, S., Nagashima, K., Fukuda, K., Fujiwara, H., Ogawa, E., Fujita, Y., Ueda, N., Matsuyama, F., Yamada, Y., Seino, Y. and Inagaki, N. (2007) The Spontaneously Diabetic Torii Rat with Gastroenteropathy. Diabetes Research and Clinical Practice, 75, 127-134. https://doi.org/10.1016/j.diabres.2006.06.034

[71] Matsumoto, Y., Torimoto, K., Matsuyoshi, H., Hirayama, A., Fujimoto, K., Yoshimura, N. and Hirao, Y. (2009) Long-Term Effects of Diabetes Mellitus on Voiding Function in a New Model of Type 2 Diabetes Mellitus, the Spontaneously Diabetic Torii (SDT) Rat. Biomedical Research, 30, 331-335. https://doi.org/10.2220/biomedres.30.331

[72] Fujii, H., Hamada, Y. and Fukagawa, M. (2008) Bone Formation in Spontaneously Diabetic Torii-Newly Established Model of Non-Obese Type 2 Diabetes Rats. Bone, 42, 372-379. https://doi.org/10.1016/j.bone.2007.10.007

[73] Kimura, S., Sasase, T., Ohta, T., Sato, E. and Matsushita, M. (2012) Characteristics of Bone Turnover, Bone Mass and Bone Strength in Spontaneously Diabetic Torii-Lepr ${ }^{\text {fa }}$ Rats. Journal of Bone and Mineral Metabolism, 30, 312-320. https://doi.org/10.1007/s00774-011-0324-2

[74] Ohta, T., Miyajima, K., Shinohara, M., Yamamoto, T. and Yamada, T. (2011) Inhibition of Postprandial Hyperglycemia Prevents the Incidence of Diabetes in Spontaneously Diabetic Torii (SDT) Rats. Journal of Animal and Veterinary Advances, $11,1583-1587$.

[75] Kishi, H., Komatsu, W., Miura, Y., Kawanobe, T., Nonaka, T. and Ohhira, S. (2010) Effects of Habitual Perilla (shiso) Tea Drinking on the Incidence of Diabetes Melli- 
tus in Spontaneously Diabetic Trii (SDT) Rats. Bioscience, Biotechnology, and Biochemistry, 74, 2490-2493. https://doi.org/10.1271/bbb.100369

[76] Sasase, T., Morinaga, H., Abe, T., Miyajima, K., Ohta, T., Shinohara, M., Matsushita, M. and Kakehashi, A. (2009) Protein Kinase C Beta Inhibitor Prevents Diabetic Peripheral Neuropathy, But Not Histopathological Abnormalities of Retina in Spontaneously Diabetic Torii Rat. Diabetes, Obesity and Metabolism, 11, 1084-1087. https://doi.org/10.1111/j.1463-1326.2009.01082.x

[77] Sjolie, A.K., Klein, R., Porta, M., Orchard, T., Fuller, J., Parving, H.H., Bilous, R. and Chaturvedi, N. (2008) Effect of Candesartan on Progression and Regression of Retinopathy in Type 2 Diabetes (DIRECT-Protect 2): A Randomised Placebo-Controlled Trial. The Lancet, 372, 1385-1393. https://doi.org/10.1016/S0140-6736(08)61411-7

[78] Hasegawa, G., Fukui, M., Hosoda, H., Asano, M., Harusato, I., Tanaka, M., Shiraishi, E., Senmaru, T., Sakabe, K., Yamasaki, M., Kitawaki, J., Fujinami, A., Ohta, M., Obayashi, H. and Nakamura, N. (2009) Telmisartan, an Angiotensin II Type 1 Receptor Blocker, Prevents the Development of Diabetes in Male Spontaneously Diabetic Torii Rats. European Journal of Pharmacology, 605, 164-169.

https://doi.org/10.1016/j.ejphar.2009.01.001

[79] Sugiyama, T., Okuno, T., Fukuhara, M., Oku, H., Ikeda, T., Obayashi, H., Ohta, M., Fukui, M., Hasegawa, G. and Nakamura, N. (2007) Angiotensin II Receptor Blocker Inhibits Abnormal Accumulation of Advanced Glycation End Products and Retinal Damage in a Rat Model of Type 2 Diabetes. Experimental Eye Research, 85, 406-412. https://doi.org/10.1016/j.exer.2007.06.008

[80] Kakehashi, A., Takezawa, M., Toyoda, F., Kinoshita, N., Kambara, C., Yamagami, H., Kato, N., Ishikawa, S.E., Kawakami, M. and Kanazawa, M. (2011) Aldose Reductase Inhibitor Fidarestat Prevents Diabetic Ocular Complications in Spontaneously Diabetic Torii Rats. The Open Diabetes Journal, 4, 101-107. https://doi.org/10.2174/1876524601104010101

[81] Ota, A., Kakehashi, A., Toyoda, F., Kinoshita, N., Shinmura, M., Takano, H., Obata, H., Matsumoto, T., Tsuji, J., Dobashi, Y., Fujimoto, W.Y., Kawakami, M. and Kanazawa, Y. (2013) Effects of Long-Term Treatment with Ranirestat, a Potent Aldose Reductase Inhibitor, on Diabetic Cataract and Neuropathy in Spontaneously Diabetic Torii Rats. Journal of Diabetes Research, 2013, Article ID: 175901.

https://doi.org/10.1155/2013/175901

[82] Toyoda, F., Kakehashi, A., Hashimoto, K., Kinoshita, N., Kambara, C., Yamagami, H., Takemoto, H., Ishikawa, S.E., Dobashi, Y., Kawakami, M. and Kanazawa, M. (2011) Accumulation of AGEs and VEGF in Eyes of SDT Rats. The Open Diabetes Journal, 4, 41-44. https://doi.org/10.2174/1876524601104010041

[83] Kinoshita, N., Kakehashi, A., Dobashi, Y., Ono, R., Toyoda, F., Kambara, C., Yamagami, H., Kitazume, Y., Kobayashi, E., Osakabe, Y., Kudo, M., Kawakami, M. and Kanazawa, M. (2011) Effects of Topical Nipradilol on Early Diabetic Retinopathy in SDT Rats. The Open Diabetes Journal, 4, 114-118. https://doi.org/10.2174/1876524601104010114 